

\title{
Los pobres
}

$0.0 \sim \%$

Los pobres son muchos

y por eso

es imposible olvidarlos.

\author{
Seguramente \\ ven \\ en los amaneceres \\ múltiples edificios \\ donde ellos \\ quisieran habitar con sus hijos.
Pueden
llevar en hombros
el féretro de una estrella.
Pueden \\ destruir el aire como aves furiosas, \\ nublar el sol. \\ Pero desconociendo sus tesoros \\ entran y salen por espejos de sangre; \\ caminan y mueren despacio.
}

Por eso

es imposible olvidarlos.

$0.2 \sim 6$

\section{Roberto Sosa}




\section{Tipología y clasificación de los hogares hondureños, periodo 2001 y 2017

\author{
Héctor Alcides Figueroa Escobar ${ }^{1}$ \\ DOI: $10.5377 / p d a c . v 14 i 0.6853$ \\ Recibido: 07/05/2018Ａceptado: 29/06/2018
}

Resumen: En las últimas décadas los hogares hondureños han sufrido una serie de transformaciones demográficas, económicas y sociales que afectan la composición y distribución de los hogares. Este artículo presenta la tipología de la pobreza de los hogares hondureños analizada en dos momentos del tiempo año 2001 y 2017 en base a los datos de la Encuesta Permanente de Hogares de Propósitos Múltiples (EPHPM). Para efectos de este estudio se establecieron cinco tipos de hogares, unipersonales, biparentales, monoparentales, extensos y compuestos. Para la estimación de la pobreza se utilizó el método de Línea de la Pobreza (LP). Para complementar el análisis de la pobreza por el método de Línea de la Pobreza y contar con indicadores sintéticos se utilizó el Índice de Foster-Greer-Thorbecke (FGT) que permite por medio de los ingresos cuantificar que tan pobres son los pobres, dicho de otra manera, cuál sería el nivel de ingreso que requieren los hogares que están en pobreza para salir de la línea de la pobreza o pobreza cero. A lo largo de 16 años los hogares hondureños registran cambios importantes en la estructura y los arreglos que se dan a lo interno de los mismos. Los hogares que prevalecen a nivel nacional son: los biparentales y los extensos. En el período de estudio se observa un crecimiento de los hogares monoparentales, por otro lado, hay diferencias marcadas que se dan en la zona urbana y la zona rural, los hogares monoparentales son más comunes en la zona urbana donde las jefaturas en su mayoría son mujeres.

Palabras Claves: Tipología de hogar, brecha, severidad e incidencia de la pobreza, pobreza relativa, pobreza extrema, ingreso per cápita.

\section{Typology and classification of Honduran homes, period 2001-2017}

Abstract: in recent decades, Honduran homes have undergone a series of demographic, economic and social transformations that affect the composition and distribution of homes. This article presents the typology of the poverty of the Honduran homes analyzed in two moments of the time year, 2001 and 2017, based on the data of the permanent survey of homes of multiple purposes (EPHPM). For the purposes of this study five types of homes were established, unipersonal, biparental, monoparent, extended and composed. The poverty line method (LP) was used for the estimation of poverty. To complete the poverty analysis by the poverty line method and to have synthetic indicators, the Foster-Greer-Thorbecke index (FGT) was used, which allows by means of the income to quantify how poor the poor are, in other words It would be the level of income that homes in poverty need to leave the poverty line or zero poverty. Over the course of 16 years, Honduran homes have register important changes in the structure and arrangements that are given to the internal ones. The homes that prevail at the national level are: the biparental and the extensive ones, in the period of study one observes a growth of the uniparental households. On the other hand, there are noticeable differences that occur in the urban area and rural areas, single-parent households are more common in the urban area where the headquarters are mostly female.

Key Words: Typology of home, Gap, severity and incidence of poverty, relative poverty, extreme poverty, Income per capita.

\section{Introducción}

El presente artículo estudia los diversos arreglos que se dan a lo interno de los hogares hondureños desde una perspectiva demográfica. Se considera la tipología de hogares y las condiciones de pobreza medida a través del método de la Línea de la Pobreza². La investigación permite cuantificar los niveles de pobreza y precariedad que viven la mayoría de los hogares hondureños tanto en el área urbana como rural.

El concepto de hogar y jefatura de hogar es relevante, en las Encuestas de Hogares se utiliza como referencia para identificar la relación de parentesco de las personas respecto del jefe del hogar. El Instituto Nacional de Estadísticas (INE) define hogar como aquel que está conformado por una persona o grupos de personas, con o sin vínculos de parentesco que habitan la misma vivienda y que al menos para la alimentación dependen de un mismo presupuesto (olla común). Así mismo define como jefe de hogar a la persona a quien los demás miembros del hogar reconocen como tal, independientemente de su sexo, contribución a la economía familiar y que ejerce autoridad para tomar decisiones que afecten o mejoren al grupo.

Honduras se encuentra en plena transición demográfica esta etapa genera cambios que son evidentes y se reflejan en la estructura de las edades de la población, impactando en la conformación de los hogares; observándose a lo interno transformaciones a lo largo de los 16 años de estudio.

1 Máster en Demografía Social - UNAH, Lic. en Economía- UNAH, Docente Investigador de la MDD-ODU-UNAH, e-mail: hectorecon@yahoo.es 2 El método establece a partir de los ingresos de los hogares, la capacidad de satisfacer, por medio de la compra de bienes y servicios un conjunto de necesidades alimentarias y no alimentarias consideradas como básicas. 
Los hogares que prevalecen a nivel nacional son: los biparentales y los extensos, en el período de estudio se observa un crecimiento de los hogares monoparentales. Clasificar los hogares según tipología y cruzarlo con los niveles de pobreza brinda una radiografía de las condiciones en las que viven el $64.3 \%$ de los hogares, también permite identificar entre los hogares que viven en condición de pobreza las brechas; para ello se utilizó los indicadores definidos en 1984 por Foster, Greer y Thorbecke conocidos como (FGT) en los que se mide la incidencia, brecha, intensidad y severidad de la pobreza.

\section{Metodología}

Para el desarrollo de la presente investigación se hizo uso de los datos de la EPHPM relevada por el INE de mayo de 2001 y 2017.

\subsection{Tipología de los hogares}

Para la construcción de la tipología de los hogares unipersonales, biparentales, monoparentales, extensos y compuesto se utilizaron las variables "Relaj" que define la relación de parentesco con el jefe del hogar y la variable "tipo de hogar" esta relación da origen a la tipología de los hogares hondureños.

- Hogares unipersonales: se define como aquellos hogares compuestos por una sola persona. Se trata de hombres y mujeres, solteros, en pareja, separados, divorciados o viudos que viven solos.

- Hogares biparentales: se definen como aquellos hogares compuestos por los cónyuges independientemente del estado civil, integrado por uno a más hijos.

- Hogares monoparentales: se define como aquellos hogares formados por un progenitor (padre o madre) y uno o varios hijos.

- Hogares extensos: se definen como aquellos hogares compuestos por los cónyuges (jefe o jefa) hijos o hijas más otros parientes (hijastros, padres, hermanos, nietos, abuelos, sobrinos, primos, etc.).

- Hogares compuestos: se define como aquellos hogares nucleares o extendidos en donde los integrantes pueden o no tener parentesco con el jefe o jefa del hogar. ${ }^{3}$
Cuadro №1 Operacionalización de variables Tipología de los hogares hondureños

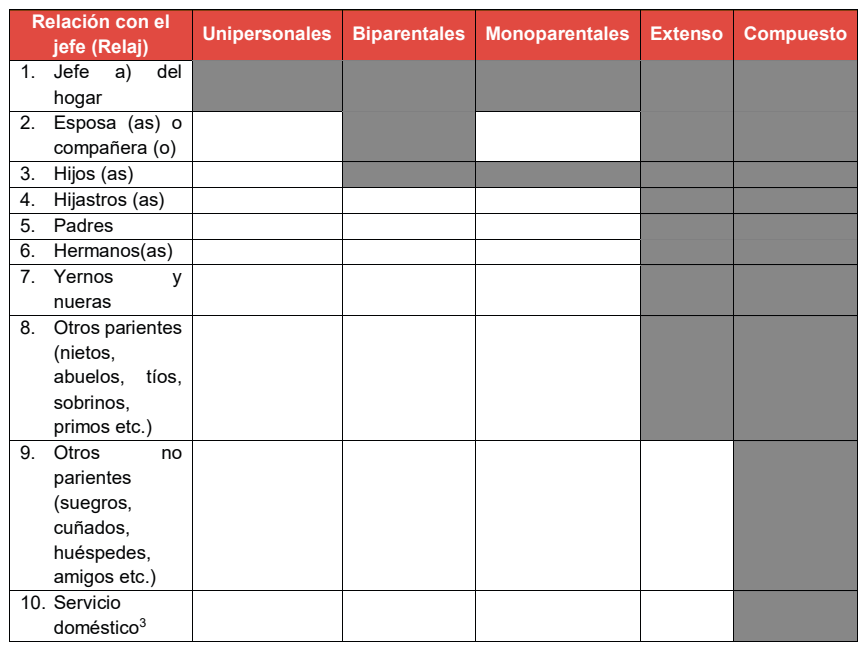

Fuente: Elaboración propia en base a metodología INE

\subsection{Estimación de la pobreza}

Para la estimación de la pobreza se utilizó el método de Línea de la Pobreza (LP). En el cálculo de la pobreza basada en hogares intervienen dos variables fundamentales: el ingreso per cápita de los hogares, que a su vez se compone de un ingreso laboral y otros ingresos, y la línea de pobreza, que se mide a partir del costo per cápita de la canasta básica familiar que incluye insumos alimentarios y no alimentarios considerados básicos.

Con el propósito de mejorar la captación de los ingresos de los hogares el INE implementó modificaciones a la boleta de la EPHPM para captar de forma más detallada otro tipo de ingresos aparte del ingreso laboral en los hogares hondureños.

Para analizar la robustez de los resultados de captación de otros ingresos en los hogares, en febrero de 2007, el INE solicitó al Banco Mundial una revisión de la metodología de la medición de la pobreza en Honduras y de este informe se obtienen conclusiones, destaca el cambio metodológico ${ }^{4}$ para la estimación de pobreza y se recomienda que, "los ajustes que se hacen a los ingresos reportados para compensar por sub-declaración y sub-captura fueron estimados hace más de 15 años y muy posiblemente no reflejen la realidad de Honduras hoy en día" (Banco Mundial, 2008).

3 Las empleadas domésticas generalmente se ubican en los hogares compuestos ya que en su mayoría no tienen ninguna relación de parentesco con el jefe o jefa del hogar.

4 Elaboración propia en base a INE; XXXVIII EPHPM, Resumen Ejecutivo, mayo 2009 y Banco Mundial (2008), Informe sobre la revisión de la medición de la Pobreza en Honduras. Tegucigalpa. 
Tomando en cuenta las recomendaciones del Banco Mundial, a partir del año 2008, se dejan de aplicar los factores de ajuste y se toma como base la captación detallada de los otros ingresos, para el cálculo del ingreso per cápita del hogar. Esto a su vez permite contar con un mayor número de observaciones, puesto que en la operación se incluyen todos los hogares que reportan ingresos y no solamente los que reportan ingreso laboral en la ocupación principal.

\subsection{Incidencia de la pobreza}

Número de personas indigentes ${ }^{5}$ expresado como porcentaje del total de la población en un determinado año. La incidencia de la indigencia se calcula mediante el índice de Foster-Greer-Thorbecke (FGT) cuya fórmula es la siguiente:

$$
P_{x}=\frac{1}{n} \sum_{n=1}^{q}\left[\frac{\left(z-y_{i}\right)}{z}\right]^{n}
$$

donde:

yi = consumo per cápita (estimado como el total del consumo del hogar dividido para el número de miembros) del individuo $\mathrm{i}(\mathrm{i}=1,2, \mathrm{q})$, considerando sólo a quienes cuyo consumo es inferior a la línea de indigencia.

$\mathrm{n}=$ Población total.

$q=$ Número total de indigentes.

z= Línea de Indigencia o extrema pobreza.

$a(a l p h a)=$ Número real no negativo, que puede tomar tres valores 0 , 1 ó 2 .

$\mathrm{P}$ es un promedio (sobre la población total, $\mathrm{n}$ ) de las distancias que separan a individuos u hogares de la línea de indigencia o extrema pobreza, ponderado por un exponente.

El valor del exponente permite que la misma fórmula dé como resultado la incidencia, brecha y severidad de la extrema pobreza o indigencia como casos especiales de la medida. Cuando vale cero, y representa la incidencia de la indigencia, es decir cuenta el número de individuos que están por debajo de la línea de extrema pobreza independientemente de sus distancias a ella.

$$
P_{a=0}=q / n
$$

\subsection{Brecha de la pobreza}

Diferencia agregada entre el consumo de las personas (u hogares) indigentes y el valor de una canasta básica de alimentos (o línea de indigencia), expresada como proporción de este último valor y dividida para la población total.

La brecha de la indigencia refleja cuan extrema es la pobreza de la población indigente y, por tanto, proporciona una idea de la profundidad de las carencias de ingreso o consumo que definen una situación de indigencia. $Y$ representa el déficit promedio de consumo de la población total para satisfacer las necesidades nutricionales mínimas de todos sus integrantes (expresado como proporción de la línea de indigencia), donde el déficit de la población no indigente es cero por definición.

Se calcula mediante el Índice de Foster-Greer-Thorbecke (FGT) cuya fórmula es la siguiente:

$$
P_{x}=\frac{1}{n} \sum_{n=1}^{q}\left[\frac{\left(z-y_{i}\right)}{z}\right]^{z}
$$

donde:

yi = consumo per cápita (estimado como el total del consumo del hogar dividido para el número de miembros) del individuo $i(i=1,2, q)$, considerando sólo a quienes cuyo consumo es inferior a la línea de indigencia.

$\mathrm{n}=$ Población total.

$q=$ Número total de indigentes.

z=Línea de indigencia o extrema pobreza.

$\mathrm{a}(\mathrm{alpha})=$ Número real o negativo, que puede tomar tres valores: 0,1 ó 2

$P$ es un promedio (sobre la población total, $n$ ) de las distancias que separan a individuos $u$ hogares de la línea de pobreza, ponderado por un exponente. El valor del exponente permite que la misma fórmula dé como resultado la incidencia, brecha y severidad de la extrema pobreza como casos especiales de la medida. Cuando vale uno, P1 representa la intensidad (o brecha) de la indigencia.

\subsection{Severidad de la Pobreza}

Es la suma ponderada de las diferencias, expresadas como porcentaje de la línea de indigencia, entre el consumo de las personas (u hogares) indigentes y el valor de una canasta básica de alimentos (o línea de indigencia), dividida para la población total.

5 Se define como "indigentes" a aquellas personas que pertenecen a hogares cuyo consumo per cápita, en un período determinado, es inferior a la línea de indigencia o extrema pobreza. La linea de indigencia es el equivalente monetario del costo de una canasta de alimentos que permita satisfacer los requerimientos nutricionales de un hogar. 
Las diferencias del consumo de cada persona (u hogar) respecto de la línea de indigencia son ponderadaselevándolas al cuadrado. El propósito de esta ponderación es dar mayor peso en la medida a las personas (u hogares) con las mayores diferencias, es decir, a aquellos más indigentes. De esta manera, la medida, además de reflejar cuánto les falta a los hogares para satisfacer sus necesidades alimenticias mínimas (la brecha de la indigencia), toma en cuenta las desigualdades o diferencias en la capacidad de consumo que existen entre los indigentes.

Se calcula mediante el Índice de Foster-Greer-Thorbecke (FGT) cuya fórmula es la siguiente:

$$
P_{x}=\frac{1}{n} \sum_{n=1}^{q}\left[\frac{\left(z-y_{i}\right)}{z}\right]^{z}
$$

donde:

yi = consumo per cápita (estimado como el total del consumo del hogar dividido para el número de miembros) del individuo $\mathrm{i}(\mathrm{i}=1,2, \mathrm{q})$, considerando sólo a quienes cuyo consumo es inferior a la línea de indigencia.

$\mathrm{n}=$ Población total.

$q=$ Número total de indigentes.

z=Línea de indigencia o extrema pobreza.

$\mathrm{a}(\mathrm{alpha})=$ Número real o negativo, que puede tomar tres valores: 0,1 ó 2

P es un promedio (sobre la población total, $n$ ) de las distancias que separan a individuos $u$ hogares de la línea de indigencia o extrema pobreza, ponderado por un exponente. El valor del exponente permite que la misma fórmula dé como resultado la incidencia, brecha y severidad de la extrema pobreza como casos especiales de la medida. Cuando vale dos (cuando las diferencias individuales de cada miembro de la población se elevan al cuadrado), P2 representa la severidad de la indigencia.

\section{Análisis de resultados}

La información de la tipología de los hogares hondureños permite conocer los diversos arreglos que se dan en los hogares, que son expresión de la prevalencia de variados patrones de arreglos familiares ligados a factores demográficos, sociales y culturales. A continuación, se presentan los principales resultados de la investigación.

\subsection{Jefatura de hogar según zona de residencia}

En Honduras históricamente ha predominado la jefatura de hogar masculina, este es un patrón difícil de revertir, pese a ello se observan algunos cambios que reflejan un aumento de la jefatura femenina lo que puede estar relacionado con dos factores: la modificación de los patrones de constitución familiar y el rol femenino dentro y fuera del espacio doméstico.

Según datos de la EPHPM de mayo de 2001, en Honduras y específicamente en la zona urbana, había 622,315 hogares con predominio de las jefaturas de hombres que representaron el $70 \%$ y un $30 \%$ de los hogares reconocen como jefa de hogar a una mujer. Para 2017 el número de hogares pasó a 1,162,381 registrando un incremento de 540,066 nuevos hogares. 16 años después siguen predominando la jefatura masculina con $62 \%$, frente a la jefatura femenina con $38 \%$ (Cuadro $\mathrm{N}^{\circ} 1$ ).

En 2001, en el área urbana la estructura de los hogares según edades quinquenales revela datos interesantes, el $47.2 \%$ de los hogares tenían un jefe de hogar hombre entre las edades de 20 a 49 años, en este rango de edad predominan las jefaturas masculinas en mayor proporción que las jefaturas femeninas, en el caso de los hogares que eran jefeados por una mujer representó apenas el 15.4\%. En 2017, el $37.4 \%$ de los hogares del área urbana cuyo jefe era hombre estaba entre los 20 y 49 años este porcentaje se reduce respecto del 2001 en 9.8 puntos porcentuales, por otra parte, las jefaturas femeninas entre 20 y 49 años representaron $17.6 \%$ de los casos presentando un incremento de 7.8 puntos porcentuales respecto del 2001 (Gráfico N 1). En otras palabras, se están generando cambios en la jefatura de los hogares urbanos con un ligero incremento de la jefatura femenina en todos los rangos de edad.

El crecimiento de hogares en el área urbana tiene impacto demográfico, económico y social. En lo que respecta al impacto demográfico este proceso de transición conlleva a un descenso sostenido de la fecundidad y la mortalidad, ya que respecto a las décadas anteriores las personas tienen mayor acceso a educación y salud; sin embargo, este proceso se complica cuando se registran altos niveles de crecimiento en las zonas denominadas urbano marginales, zonas que en su mayoría pasan a ocupar los miembros de hogares migrantes rurales, el hacinamiento es otro 
problema causado por el elevado número de habitantes en las viviendas respecto a la cantidad de habitaciones. Otro problema es el asentamiento precario ya que es una forma de hábitat generado por las dificultades para acceder a la propiedad legal de los terrenos urbanos. En cuanto al impacto económico de la transición de los hogares rurales al área urbana destaca, por un lado, la baja productividad, mano de obra no calificada que viene a engrosar el sector servicios donde se trabaja largas jornadas y se obtienen remuneraciones precarias que no cubren el costo de la canasta básica de alimentos. El proceso de urbanización conlleva un sin número de riesgos sociales como el incremento de la criminalidad, la violencia, la pobreza entre las más relevantes.

En la zona rural los datos de la EPHPM de mayo de 2001 registraron 627,657 hogares, $79 \%$ correspondía a jefaturas de hombres y $21 \%$ reconocían como jefa de hogar a una mujer. En 2017 se identificaron 897,784 hogares en la zona rural, $75 \%$ con jefatura masculina y un $25 \%$ de los hogares con jefatura femenina. Entre ambos años se registró un incremento de 270,127 nuevos hogares.

Para los hogares rurales en 2001 las jefaturas de hogar entre las edades de 20 a 49 años, 49.2\% tenían a un jefe hombre y el $9.8 \%$ tenía como jefa a una mujer. En 2017, la estructura por edad se ha modificado a lo interno de cada quinquenio, el $44.0 \%$ de los hogares jefeados por hombres tenían entre 20 y 49 años, y el $11.6 \%$ las jefas eran mujeres. En cada quinquenio los jefes de hogar hombres son mayoría es una tendencia que se mantiene respecto de 2001. En los hogares donde el jefe tenía 50 años o más, el 30.2\% de los hogares tenían como jefe de hogar a un hombre y el $13.7 \%$ a una mujer en ambos casos se ha incrementado el número de jefes y jefas de hogar (Gráfico $\left.N^{\circ} 2\right)$.

Gráfico № 1 Honduras: pirámide de población de los hogares hondureños urbanos 2001 y 2017
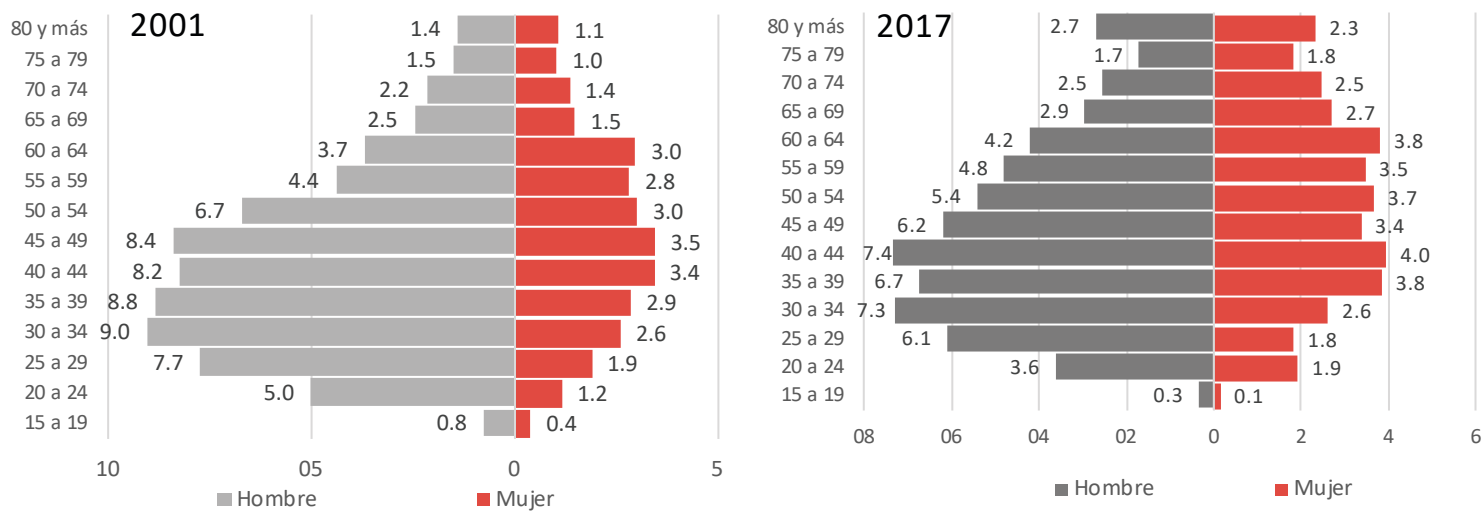

Fuente: Elaboración propia en base a datos de la EPHPM, INE 2001 y 2017

Gráfico № 2 Honduras: pirámide de población de los hogares hondureños rurales 2001 y 2017
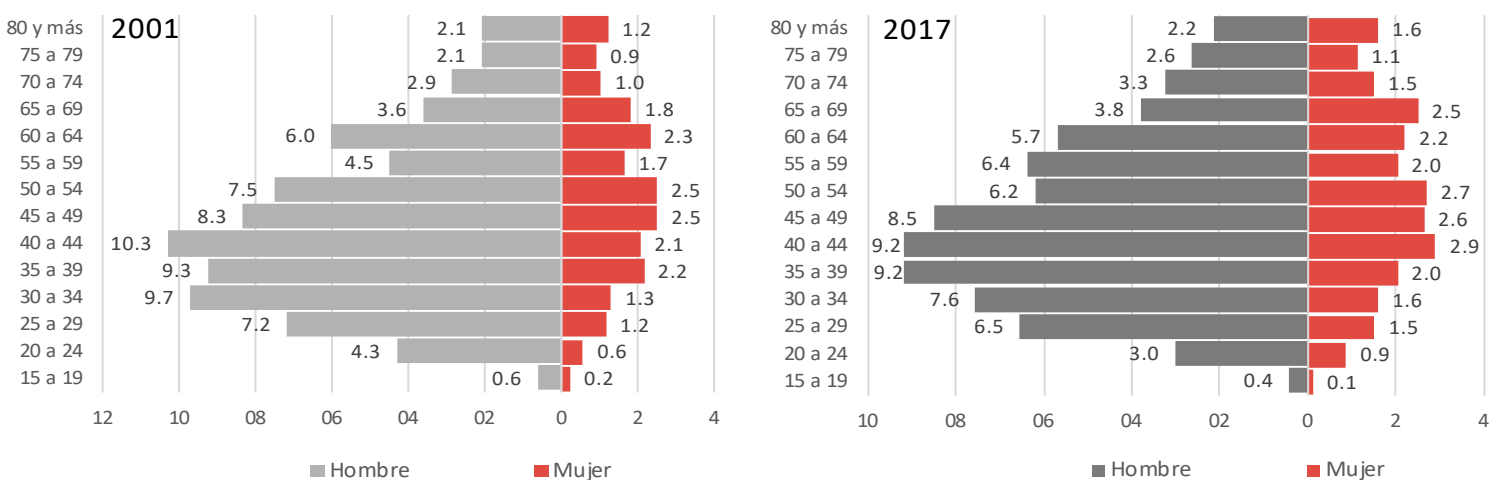
El proceso de envejecimiento afecta tanto a jefes y jefas del área rural como a los del área urbana, sin embargo, las jefaturas más envejecidas se dan en mayor medida en los hogares del área rural, el $40.2 \%$ de las jefaturas ya sean hogares jefeados por hombres o mujeres tenían una edad mayor o igual a 50 años, desagregado por sexo se observó que el $28.7 \%$ de las jefaturas de hogares eran hombres y el $11.5 \%$ tenían como jefa a una mujer (Gráfico $N^{\circ} 2$ ).

\subsection{Tipología de los hogares}

Cuando se habla de hogar se alude a "una organización estructurada entre individuos unidos o no por lazos de parentesco, que comparten una residencia y organizan en común la reproducción cotidiana". Familia "remite a una institución constituida a partir de relaciones de parentesco, normadas por pautas y prácticas sociales establecidas. La institución familiar como espacio de interacción, rebasa la unidad residencial (la vivienda) pero como ámbito privilegiado de la reproducción biológica y socialización primaria de los individuos, puede implicar la co-residencia (De Oliveira, 1982).

Ambos conceptos, hogar y familia, no pueden usarse como sinónimos, porque el hogar no necesariamente implica parentesco y sus redes se concretan al espacio en la unidad residencial, familia en cambio implica parentesco y sus redes rebasan dicha unidad. Además, en las familias se incluye el sustrato biológico ligado a las relaciones generacionales, la afectividad, la sexualidad y la procreación, constituyéndose en la institución social que regula, canaliza y confiere significados sociales y culturales a esos cuatro aspectos. Mientras tanto, los hogares se definen por las actividades comunes ligadas al mantenimiento cotidiano, que combinan las capacidades de los miembros con los recursos para realizar las tareas de producción y distribución (Fonseca, 2013).
En la EPHPM la identificación de hogares y tipologías de hogares comienza en la sección IV. Composición del Hogar, donde se da inicio a la identificación de los residentes de la vivienda, luego se distingue la relación de parentesco de las personas que habitan la vivienda en relación con el jefe de hogar, se identifica si hay más de un hogar en la vivienda. La encuesta recolecta información de un hogar o varios hogares en particular al interior de la vivienda. La información que brinda la EPHPM permite conocer los diversos arreglos y estructura de los hogares hondureños, que son la expresión de patrones de organización y reproducción familiares, ligados a factores demográficos.

En Honduras en el 2001 había 1,249,972 hogares de los cuales $74 \%$ reconocían como jefe de hogar a un hombre (930,361 hogares) y $26 \%$ reconocían como jefa a una mujer $(319,611)$, los hogares agrupan diversos arreglos de las personas que pueden ser diferenciados de acuerdo con las relaciones de parentesco con el jefe del hogar.

En el país prevalecen los hogares biparentales (48.6\%) que son aquellos hogares que están conformados por ambos cónyuges e hijos. Otro tipo de hogares son los extensos (33.1\%) que son aquellos hogares compuestos por los cónyuges (jefe o jefa) hijos o hijas más otros parientes (hijastros, padres, hermanos, nietos, abuelos, sobrinos, primos, etc.). También están los monoparentales (10.8\%), seguido de los unipersonales $(5.0 \%)$, los menos comunes son los hogares compuestos (2.5\%) (Cuadro N 1, Gráfico N³).

Desagregando esta variable por sexo, a nivel nacional del total de hogares donde los jefes eran hombres predominan los biparentales $(63.5 \%)$, seguido los extensos $(27.2 \%)$, los unipersonales (3.9) y los hogares menos comunes eran las jefaturas masculinas son los monoparentales $(2.8 \%)$ y los hogares compuestos con el $(2.7 \%)$. Por otro lado, del total de hogares que reconocen a una mujer como jefa de hogar prevalecen los hogares extensos (50.6\%) que

\section{Cuadro №1 Honduras: tipología de los hogares, según sexo y zona de residencia, 2001}

\begin{tabular}{|c|c|c|c|c|c|c|c|c|c|c|c|c|c|c|c|c|c|c|}
\hline \multirow{3}{*}{$\begin{array}{c}\text { Tipología de los } \\
\text { hogares }\end{array}$} & \multicolumn{6}{|c|}{ Total } & \multicolumn{6}{|c|}{ Urbano } & \multicolumn{6}{|c|}{ Rural } \\
\hline & \multicolumn{2}{|c|}{ Total } & \multicolumn{2}{|c|}{ Hombre } & \multicolumn{2}{|c|}{ Mujer } & \multicolumn{2}{|c|}{ Total } & \multicolumn{2}{|c|}{ Hombre } & \multicolumn{2}{|c|}{ Mujer } & \multicolumn{2}{|c|}{ Total } & \multicolumn{2}{|c|}{ Hombre } & \multicolumn{2}{|c|}{ Mujer } \\
\hline & Total & $\% / 1$ & Total & $\% / 1$ & Total & $\% / 1$ & Total & $\% / 1$ & Total & $\% / 1$ & Total & $\% / 1$ & Total & $\% / 1$ & Total & $\% / 1$ & Total & $\% / 1$ \\
\hline Total/2 & $1,249,972$ & $100.0 \%$ & 930,361 & $74.4 \%$ & 319,611 & $26 \%$ & 622,315 & $49.8 \%$ & 437,502 & $70 \%$ & 184,812 & $30 \%$ & 627,657 & $50.2 \%$ & 492,859 & 79\% & 134,799 & $21 \%$ \\
\hline UniPersonal & 62,128 & $5.0 \%$ & 36,121 & $3.9 \%$ & 26,008 & $8.1 \%$ & 37,021 & $5.9 \%$ & 20,661 & $4.7 \%$ & 16,361 & $8.9 \%$ & 25,107 & $4.0 \%$ & 15,460 & $3.1 \%$ & 9,647 & $7.2 \%$ \\
\hline BiParental & 607,056 & $48.6 \%$ & 590,578 & $63.5 \%$ & 16,478 & $5.2 \%$ & 283,052 & $45.5 \%$ & 272,329 & $62.2 \%$ & 10,723 & $5.8 \%$ & 324,004 & $51.6 \%$ & 318,249 & $64.6 \%$ & 5,755 & $4.3 \%$ \\
\hline MonoParental & 135,415 & $10.8 \%$ & 26,069 & $2.8 \%$ & 109,347 & $34.2 \%$ & 73,244 & $11.8 \%$ & 12,770 & $2.9 \%$ & 60,474 & $32.7 \%$ & 62,171 & $9.9 \%$ & 13,298 & $2.7 \%$ & 48,873 & $36.3 \%$ \\
\hline Extenso & 414,246 & $33.1 \%$ & 252,611 & $27.2 \%$ & 161,635 & $50.6 \%$ & 209,671 & $33.7 \%$ & 116,457 & $26.6 \%$ & 93,214 & $50.4 \%$ & 204,576 & $32.6 \%$ & 136,154 & $27.6 \%$ & 68,422 & $50.8 \%$ \\
\hline Compuesto & 31,126 & $2.5 \%$ & 24,982 & $2.7 \%$ & 6,144 & $1.9 \%$ & 19,326 & $3.1 \%$ & 15,285 & $3.5 \%$ & 4,042 & $2.2 \%$ & 11,799 & $1.9 \%$ & 9,697 & $2.0 \%$ & 2,102 & $1.6 \%$ \\
\hline
\end{tabular}


son aquellos hogares compuestos por los cónyuges (jefe o jefa) hijos o hijas más otros parientes (hijastros, padres, hermanos, nietos, abuelos, sobrinos, primos, etc.). Seguido de los monoparentales (34.2\%), y los unipersonales (8.1\%), los menos comunes entre las jefaturas femeninas son los hogares biparentales (5.2\%) y los compuestos (1.9\%) (Cuadro $\mathrm{N}^{\circ} 1$ ).

En 2017 había 1,390,929 hogares que eran jefeados por hombres registrando un incremento de 460,568 respecto a los del 2001, en el caso de los hogares que son jefeados por una mujer se observó un incremento de 349,626 situándose en 669,237 hogares. Del total de hogares jefeados por hombres los que más crecieron fueron los hogares extensos (194,822 hogares), y los biparentales (168,194 hogares), por otro lado, entre los que registran un crecimiento más moderado están los compuestos $(76,569$ hogares), los unipersonales (25,921 hogares). Los hogares monoparentales registran una caída de 4,938 esto se puede dar por varias razones, una porque pasaron a formar parte de hogares biparentales, donde los jefes o jefas de hogar decidieron conformar un hogar biparental o extenso. Otro aspecto importante es la migración hacia el extranjero de los jefes o jefas de hogar (Cuadro N², Gráfico N³).

En 2017 se registran 669,237 hogares que eran jefeados por una mujer, este comportamiento presenta cambios interesantes en la conformación de las familias y sus estructuras, los hogares que registran el mayor incremento son los extensos (153,334 hogares) y los monoparentales (102,860 hogares), los que menos crecieron fueron los biparentales (42,358 hogares), los compuestos $(27,479$ hogares) y los hogares unipersonales (23,595 hogares).

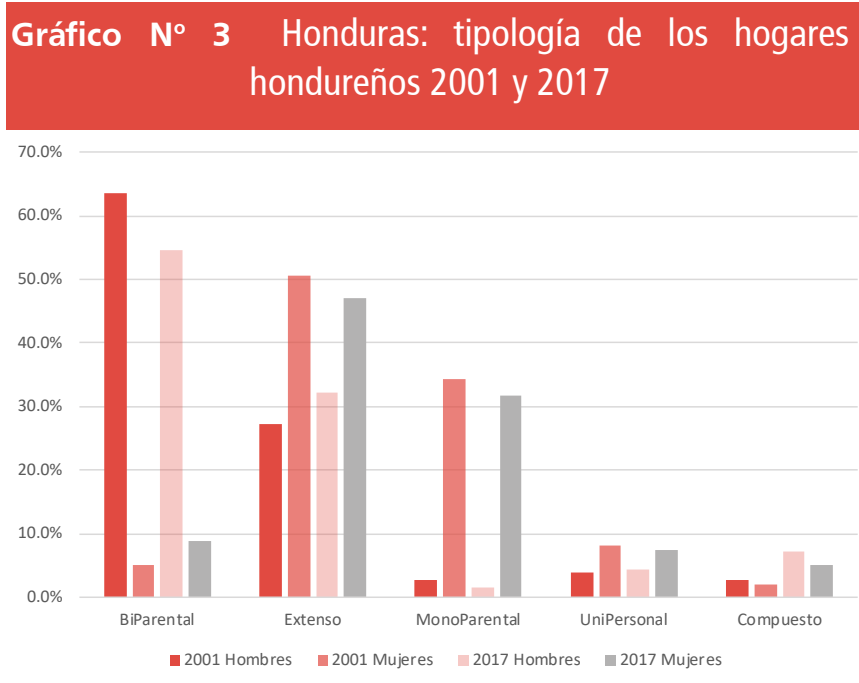

Fuente: Elaboración propia en base a datos de la EPHPM, INE 2001 y 2017

\subsection{Nivel de pobreza}

En Honduras en las últimas décadas la pobreza se acentúa más, cada año aumenta el número de hogares pobres lo que pone de manifiesto el estado carencial de la población.

La evolución de la pobreza está vinculada a los ciclos económicos, la teoría enfatiza que la pobreza puede ser un obstáculo para el crecimiento económico, en la medida en que las familias pobres tienen pocas o limitadas oportunidades para lograr mejores tasas de inversión productiva o de inversión de capital humano. De la misma manera se plantea que los países más pobres son menos atractivos para la inversión, debido a su bajo desarrollo en capital humano. Por otro lado, el crecimiento económico requiere de factores que favorezcan la competitividad entre los que destacan la inversión en infraestructura, acceso a los factores de producción tierra y capital en las zonas rurales más pobres.

Cuadro №2 Honduras: tipología de los hogares, según sexo y zona de residencia, 2017

\begin{tabular}{|c|c|c|c|c|c|c|c|c|c|c|c|c|c|c|c|c|c|c|}
\hline \multirow{3}{*}{$\begin{array}{c}\text { Tipología de los } \\
\text { hogares }\end{array}$} & \multicolumn{6}{|c|}{ Total } & \multicolumn{6}{|c|}{ Urbano } & \multicolumn{6}{|c|}{ Rural } \\
\hline & \multicolumn{2}{|c|}{ Total } & \multicolumn{2}{|c|}{ Hombre } & \multicolumn{2}{|c|}{ Mujer } & \multicolumn{2}{|c|}{ Total } & \multicolumn{2}{|c|}{ Hombre } & \multicolumn{2}{|c|}{ Mujer } & \multicolumn{2}{|c|}{ Total } & \multicolumn{2}{|c|}{ Hombre } & \multicolumn{2}{|c|}{ Mujer } \\
\hline & Total & $\% 11$ & Total & $\% 11$ & Total & $\% 11$ & Total & $\% 11$ & Total & $\% 1$ & Total & $\% 11$ & Total & $\% 1$ & Total & $\% 1$ & Total & $\% 1$ \\
\hline Total & $2,060,165$ & $100.0 \%$ & $1,390,929$ & $68 \%$ & 669,237 & $32 \%$ & $1,162,381$ & $56.4 \%$ & 721,260 & $62 \%$ & 441,121 & $38 \%$ & 897,784 & $43.6 \%$ & 669,668 & $75 \%$ & 228,116 & $25 \%$ \\
\hline UniPersonal & 111,645 & $5.4 \%$ & 62,042 & $4.5 \%$ & 49,603 & $7.4 \%$ & 66,171 & $5.7 \%$ & 37,018 & $5.1 \%$ & 29,153 & $6.6 \%$ & 45,474 & $5.1 \%$ & 25,024 & $3.7 \%$ & 20,450 & $9.0 \%$ \\
\hline BiParental & 817,608 & $39.7 \%$ & 758,772 & $54.6 \%$ & 58,836 & $8.8 \%$ & 415,999 & $35.8 \%$ & 375,310 & $52.0 \%$ & 40,689 & $9.2 \%$ & 401,610 & $44.7 \%$ & 383,462 & $57.3 \%$ & 18,148 & $8.0 \%$ \\
\hline MonoParental & 233,337 & $11.3 \%$ & 21,131 & $1.5 \%$ & 212,206 & $31.7 \%$ & 149,266 & $12.8 \%$ & 12,371 & $1.7 \%$ & 136,895 & $31.0 \%$ & 84,071 & $9.4 \%$ & 8,760 & $1.3 \%$ & 75,311 & $33.0 \%$ \\
\hline Extenso & 762,402 & $37.0 \%$ & 447,433 & $32.2 \%$ & 314,969 & $47.1 \%$ & 443,458 & $38.2 \%$ & 233,040 & $32.3 \%$ & 210,418 & $47.7 \%$ & 318,944 & $35.5 \%$ & 214,393 & $32.0 \%$ & 104,551 & $45.8 \%$ \\
\hline Compuesto & 135,173 & $6.6 \%$ & 101,551 & $7.3 \%$ & 33,622 & $5.0 \%$ & 87,487 & $7.5 \%$ & 63,521 & $8.8 \%$ & 23,966 & $5.4 \%$ & 47,686 & $5.3 \%$ & 38,029 & $5.7 \%$ & 9,657 & $4.2 \%$ \\
\hline
\end{tabular}


En 2001, el 65.2\% de los hogares estaba en condición de pobreza, ya que sus ingresos se encontraban por debajo del costo de una canasta básica de consumo que incluye alimentos y otros bienes y servicios. De este total $48.4 \%$ estaban en esta condición pobres extremos y un $16.8 \%$ estaban en condición de pobreza relativa (Gráfico $N^{\circ} 4$ ).

Según la tipología los hogares más afectados por la pobreza eran los hogares extensos, 53.9\% estaba en condición de pobreza extrema, hogares cuyo promedio de personas era 5 y sus ingresos eran insuficientes para cubrir una canasta básica de alimentos, de estos $17.4 \%$ estaban en condición pobreza relativa. Esta situación es compleja en estos hogares ya que no logran satisfacer necesidades de alimentación e ingreso. En Honduras de cada 10 hogares extensos, 7 están en condición de pobreza. La pobreza también afecta a los hogares monoparentales, el $65.8 \%$ estaba en condición de pobreza, de estos $50.0 \%$ se encontraba en pobreza extrema y el $15.8 \%$ en pobreza relativa (Gráfico $\mathrm{N}^{\circ} 4$ ).

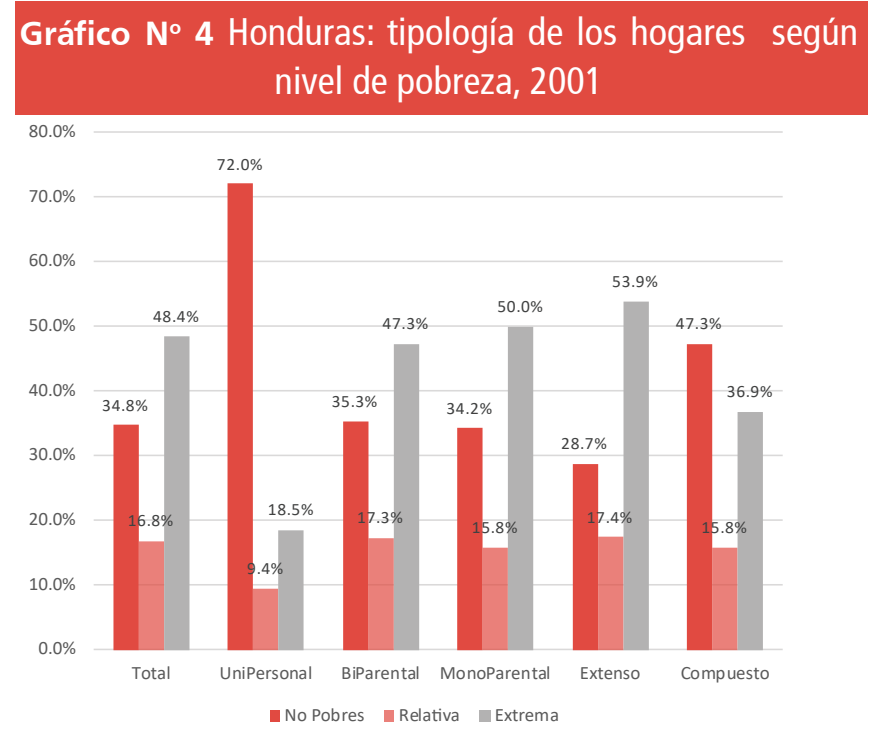

Fuente: Elaboración propia en base a datos de la EPHPM, INE 2001

En 2017 se estimaron 2,049,890 de los cuales el 64.3\% estaba en condición de pobreza, porcentualmente se registró una reducción de 0.9 puntos respecto a 2001, sin embargo, el número de hogares pobres va en aumento, pasó en el 2001 de 696,872 hogares pobres a 1,317,681 en el 2017, en 16 años se duplicó el número de hogares pobres, estimándose 620,809 nuevos hogares pobres, lo que refleja la alta concentración de los ingresos en el $20 \%$ de la población más rica. En este contexto el crecimiento económico resulta insuficiente para reducir la pobreza, debido a que el impacto de este es menor que el de sociedades menos desiguales.

En 16 años se esperaba que los niveles de pobreza en el país bajaran significativamente, sin embargo, esto no se dio por varias razones: una porque el país no ha logrado los niveles de crecimiento económico que permitan generar bienestar en la población, segundo el mercado laboral no absorbe el excedente de mano de obra y las personas que conforman la PEA dependen de salarios precarios, a esto hay que sumarle las personas con problemas de empleo que ronda el $63.0 \%$ de la PEA ocupada. Las transferencias condicionadas a los hogares más pobres no han sido efectivas, ya que no fueron entregadas a los hogares pobres y no ha contado con un mecanismo eficiente de focalización, somos un país donde se produce y se fabrica pobres ya que cada año, $82 \mathrm{mil}$ hogares entran a formar parte de la pobreza.

Cuando se desagrega la pobreza según nivel y tipología de los hogares, en 2017 el $40.7 \%$ de los hogares vivían en condición de pobreza extrema y el $23.6 \%$ estaba en condición de pobreza relativa, se presenta una reducción porcentual de 7.7 puntos en la pobreza extrema, sin embargo, esto no se traduce en menor número de hogares pobres extremos, todo lo contrario ya que los hogares que se encontraban en esta condición registraron un aumento de 317,286 hogares que pasaron de la pobreza relativa a la pobreza extrema. Los hogares que se encontraban en condición de pobreza relativa también registran un incremento, de 303,522 hogares pasaron a formar parte de los pobres, esta situación es compleja y se acentúa más en los hogares que están conformados por 5 o más personas (Gráfico $\mathrm{N}^{\circ} 5$ ).

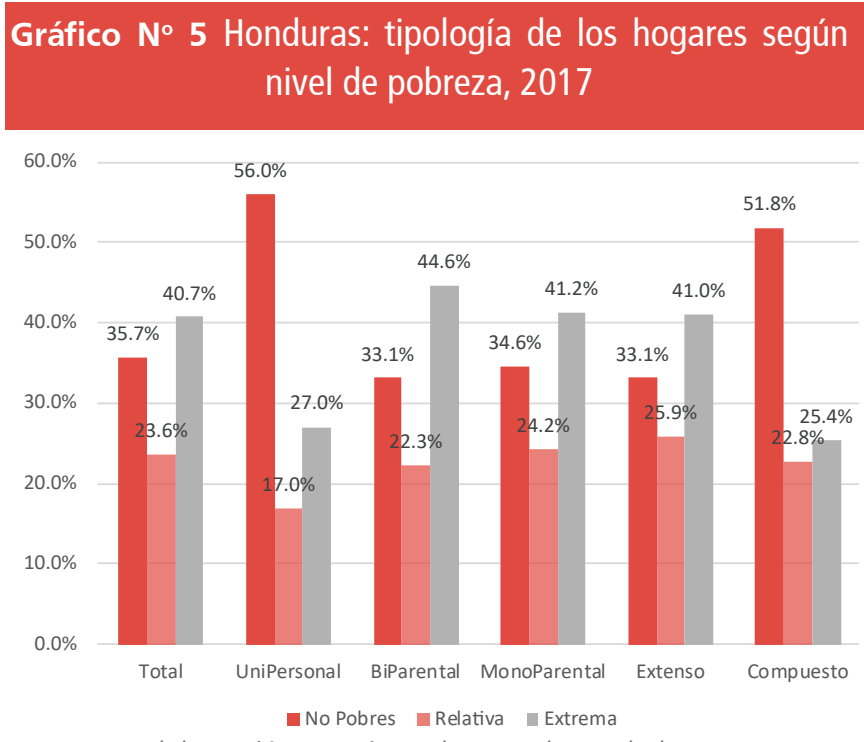

Fuente: Elaboración propia en base a datos de la EPHPM, INE 2017

Los hogares extensos son los que presentan los niveles de pobreza más alto en 2017 , el $66.9 \%$ estaban en condición de pobreza y de éstos el $41.0 \%$ eran pobres extremos y el $25.9 \%$ se encontraban en pobreza relativa. Los hogares biparentales presentan el mismo nivel de pobreza (66.9\%) que los hogares extensos, sin embargo, en la distribución del nivel de pobreza se dan cambios significativos ya que 
el $44.6 \%$ eran pobres extremos y el $22.3 \%$ pobres relativos. Del total de hogares monoparentales el $41.2 \%$ de los hogares vivían en condición de pobreza extrema y el $24.2 \%$ eran pobres relativos, estos hogares están conformados en su mayoría por jefas de hogar y el tamaño es de 3 personas y viven con ingresos menores al costo de la canasta básica de alimentos más o menos L. 10.00 diarios por persona.

Los hogares compuestos registran una disminución de 4.5 puntos porcentuales, se pasó de $52.7 \%$ de hogares pobres en 2001 a $48.2 \%$, en 2017 esta reducción porcentual no se traduce en reducir el número de hogares pobres ya que en el 2001 había 15,461 hogares en condición de pobreza y en 2017 se incrementó a 64,797, la condición de pobreza de los hogares cada vez son más frágiles ya que las familias no logran generar la cantidad de ingresos que les permita salir de esta condición, si a esto le incluimos la variable edad mediana de los y las jefes de hogar son personas que están por salir de la edad activa y esto hace más difícil su situación de pobreza de igual manera mantenerse o insertarse en el mercado laboral. En 2017 el $44.0 \%$ del total de hogares unipersonales estaban en condición de pobreza, de estos hogares, $27.0 \%$ vivían en situación de pobreza extrema, las personas que los conforman no logran completar sus ingresos para cubrir el costo de la canasta básica de alimentos, estos hogares están conformados en su mayoría por hombres, y su promedio de edad es de 66 años, en otras palabras, hogares envejecidos conformados por personas que en su vejez se quedaron solas y que su futuro no es prometedor por las condiciones en que están envejeciendo.

\subsection{Niveles de pobreza y tipología según zona de residencia y sexo del jefe del hogar}

En el cálculo de la pobreza intervienen dos variables fundamentales el ingreso per cápita de los hogares, integrado por los ingresos laborales y otros ingresos y la Línea de la Pobreza que es básicamente el costo per cápita de la canasta básica de alimentos.

En el cuadro $N^{\circ} 3$ se observa que la pobreza afecta más a los hogares del área rural, que de los del área urbana. En las zonas urbanas aquellos hogares pobres que dependen de actividades productivas y comerciales de baja productividad y con un alto nivel de informalidad son los más propensos a caer en la pobreza ya que no generan ingresos suficientes para cubrir la canasta básica y de alimentos. En las zonas rurales la pobreza afecta más a los hogares que dependen de salarios bajos y realizan actividades de baja productividad. Debido a esta situación, se requiere que el Estado genere políticas que focalicen de manera apropiada el gasto púbico hacia los sectores más pobres, especialmente los de las zonas rurales.

Cuadro №3 Honduras: nivel de pobreza y tipología según zona de residencia y sexo del jefe del hogar, 2001

\begin{tabular}{|c|c|c|c|c|c|c|c|c|c|c|c|c|}
\hline \multirow{3}{*}{\multicolumn{3}{|c|}{$\begin{array}{l}\text { Zona de Residencia/sexo } \\
\text { jefe/Clasificación de la pobreza }\end{array}$}} & \multicolumn{10}{|c|}{ Tipología } \\
\hline & & & \multicolumn{2}{|c|}{ UniPersonal } & \multicolumn{2}{|c|}{ BiParental } & \multicolumn{2}{|c|}{ MonoParental } & \multicolumn{2}{|c|}{ Extenso } & \multicolumn{2}{|c|}{ Compuesto } \\
\hline & & & Total & $\%$ & Total & $\%$ & Total & $\%$ & Total & $\%$ & Total & $\%$ \\
\hline \multirow{6}{*}{ Total } & \multirow{3}{*}{ Hombre } & Extrema & 4,520 & $10.9 \%$ & 244,564 & $46.0 \%$ & 9,398 & $8.9 \%$ & 120,822 & $33.5 \%$ & 8,440 & $28.7 \%$ \\
\hline & & Relativa & 2,579 & $6.2 \%$ & 89,550 & $16.8 \%$ & 3,647 & $3.5 \%$ & 35,722 & $9.9 \%$ & 3,292 & $11.2 \%$ \\
\hline & & No pobres & 21,601 & $52.1 \%$ & 183,065 & $34.4 \%$ & 7,882 & $7.5 \%$ & 67,956 & $18.9 \%$ & 12,109 & $41.2 \%$ \\
\hline & \multirow{3}{*}{ Mujer } & Extrema & 3,168 & $7.6 \%$ & 7,181 & $1.4 \%$ & 43,159 & $41.1 \%$ & 73,267 & $20.3 \%$ & 2,379 & $8.1 \%$ \\
\hline & & \begin{tabular}{|l|} 
Relativa \\
\end{tabular} & 1,331 & $3.2 \%$ & 2,583 & $0.5 \%$ & 12,941 & $12.3 \%$ & 26,976 & $7.5 \%$ & 1,350 & $4.6 \%$ \\
\hline & & No pobres & 8,279 & $20.0 \%$ & 4,946 & $0.9 \%$ & 28,079 & $26.7 \%$ & 35,654 & $9.9 \%$ & 1,790 & $6.1 \%$ \\
\hline \multirow{6}{*}{ Urbano } & \multirow{3}{*}{ Hombre } & Extrema & 1,924 & $7.0 \%$ & 89,595 & $33.1 \%$ & 3,669 & $6.0 \%$ & 46,126 & $23.9 \%$ & 3,240 & $17.9 \%$ \\
\hline & & \begin{tabular}{|l} 
Relativa \\
\end{tabular} & 1,323 & $4.8 \%$ & 53,766 & $19.8 \%$ & 2,445 & $4.0 \%$ & 21,697 & $11.2 \%$ & 2,319 & $12.8 \%$ \\
\hline & & No pobres & 14,225 & $52.0 \%$ & 117,561 & $43.4 \%$ & 4,648 & $7.6 \%$ & 42,612 & $22.1 \%$ & 8,754 & $48.3 \%$ \\
\hline & \multirow{3}{*}{ Mujer } & Extrema & 2,062 & $7.5 \%$ & 4,517 & $1.7 \%$ & 22,468 & $36.8 \%$ & 40,353 & $20.9 \%$ & 1,403 & $7.7 \%$ \\
\hline & & \begin{tabular}{|l} 
Relativa \\
\end{tabular} & 972 & $3.6 \%$ & 1,771 & $0.7 \%$ & 9,768 & $16.0 \%$ & 19,035 & $9.9 \%$ & 833 & $4.6 \%$ \\
\hline & & No pobres & 6,834 & $25.0 \%$ & 3,687 & $1.4 \%$ & 18,013 & $29.5 \%$ & 23,136 & $12.0 \%$ & 1,578 & $8.7 \%$ \\
\hline \multirow{6}{*}{ Rural } & \multirow{3}{*}{ Hombre } & Extrema & 2,596 & $18.4 \%$ & 154,969 & $59.4 \%$ & 5,729 & $13.0 \%$ & 74,697 & $44.6 \%$ & 5,199 & $46.3 \%$ \\
\hline & & \begin{tabular}{|l} 
Relativa \\
\end{tabular} & 1,257 & $8.9 \%$ & 35,784 & $13.7 \%$ & 1,202 & $2.7 \%$ & 14,026 & $8.4 \%$ & 973 & $8.7 \%$ \\
\hline & & No pobres & 7,376 & $52.2 \%$ & 65,504 & $25.1 \%$ & 3,234 & $7.3 \%$ & 25,344 & $15.1 \%$ & 3,354 & $29.9 \%$ \\
\hline & \multirow{3}{*}{ Mujer } & Extrema & 1,106 & $7.8 \%$ & 2,664 & $1.0 \%$ & 20,692 & $46.9 \%$ & 32,914 & $19.7 \%$ & 976 & $8.7 \%$ \\
\hline & & \begin{tabular}{|l} 
Relativa \\
\end{tabular} & 359 & $2.5 \%$ & 812 & $0.3 \%$ & 3,173 & $7.2 \%$ & 7,942 & $4.7 \%$ & 516 & $4.6 \%$ \\
\hline & & No pobres & 1,445 & $10.2 \%$ & 1,259 & $0.5 \%$ & 10,066 & $22.8 \%$ & 12,518 & $7.5 \%$ & 212 & $1.9 \%$ \\
\hline
\end{tabular}


En el 2001 los hogares más afectados por la pobreza eran los extensos, al desagregar por zona de residencia y sexo del jefe de hogar, del total de hogares que residían en la zona urbana y tenían como jefe de hogar a un hombre el $23.9 \%$ tenían un ingreso per cápita inferior al costo de la canasta básica de alimentos y el $11.2 \%$ de los hogares no cubría el costo de la canasta básica6. Por otro lado, un $20.9 \%$ de los hogares que son jefeados por una mujer eran afectados por la pobreza extrema y un $9.9 \%$ por la pobreza relativa. Los hogares jefeados por hombres son más afectados por la pobreza por la diferencia de ingreso que se da entre los sexos y otra es el tamaño de los hogares de las jefaturas femenina es 4.6 y la de los hombres es de 5.6.

En la zona urbana un $36.8 \%$ de los hogares monoparentales jefeados por una mujer estaban en pobreza extrema y un $16.0 \%$ estaban en condición de pobreza relativa, estas familias se ven afectadas por la informalidad de los trabajos en que logran insertarse, ya que son trabajos poco productivos y donde los salarios no son suficiente para salir de la pobreza. Los hogares monoparentales jefeados por hombres son menos afectados por la pobreza ya que sólo un $6.0 \%$ eran pobres extremos y un $4.0 \%$ pobres relativos.

La zona rural presenta características muy diferentes a la zona urbana y los hogares más afectados por la pobreza extrema son los jefeados por mujeres con un $46.9 \%$ y un $7.2 \%$ son pobres relativos, en cambio aquellos hogares que identifican a un hombre como el jefe del hogar sólo el $13.0 \%$ estaban en una condición de extrema pobreza y un $2.7 \%$ eran pobres relativos.

Los hogares biparentales son aquellos compuestos por ambos cónyuges e hijos(as) en 2001 en la zona urbana un $33.1 \%$ de los hogares cuyo jefe era un hombre vivían en condición de pobreza extrema y un $19.8 \%$ no generaron los ingresos suficientes para cubrir el costo de la canasta básica, los hogares que prevalecen en la zona urbana son los jefeados por hombres, sin embargo, aquellos hogares que son jefeados por mujeres también son afectados por la pobreza el $1.7 \%$ su ingreso per cápita era inferior al costo de la canasta básica de alimentos y un $0.7 \%$ sus ingresos no cubrían el costo de la canasta básica.

En la zona rural se presenta una mayor incidencia de la pobreza en los hogares que son jefeados por hombres donde el $59.4 \%$ vivían en la extrema pobreza y un $13.7 \%$ en pobreza relativa. En cambio, aquellos hogares donde las jefas eran mujeres y su ingreso per cápita era menor al costo de la canasta básica de alimentos sólo afecto al $1.0 \%$ y un $0.3 \%$ eran hogares en condición de pobreza relativa.

La pobreza sigue afectando a los diferentes tipos de hogares y una de las características que persiste es la desigualdad en el ingreso lo que supone la concentración en el $20 \%$ de la población más rica; el área rural es la más afectada ya que son zonas relegadas y de baja productividad las familias que habitan en esta zona no tienen oportunidades de mejorar sus condiciones de vida.

En 2017 la tendencia de la pobreza no cambia, 16 años después la pobreza sigue siendo mayor en las áreas rurales que en las urbanas. Un aspecto relevante es que el tamaño de los hogares se ha reducido en ambas zonas, sin embargo, el promedio de personas por hogar sigue siendo mayor en las zonas rurales que en las urbanas.

Las condiciones de pobreza aumentan conforme las familias de los hogares envejecen, los jefes de hogar hombres o mujeres de mayor edad presentan grandes dificultades para mantenerse en el mercado laboral o ingresar al mismo, una alta proporción de adultos no cuenta con sistemas de previsión social y esto aumenta el riesgo de caer bajo los umbrales de pobreza. Los avances en la reducción de la pobreza han sido lentos, en 2017 los hogares más afectados fueron los hogares extensos y los biparentales, en la zona urbana los hogares que son jefeados por hombres siguen presentando los niveles de pobreza extrema y relativa más alta, misma tendencia se presenta en la zona rural donde los hogares presentan un mayor número de miembros y las condiciones son precarias.

El nivel de pobreza en los hogares monoparentales mantiene los mismos niveles observados en el 2001 lo que es preocupante ya que la mayoría está constituida por mujeres que crían sus hijos solas, las dificultades económicas que enfrentan estas jefas de hogar se debe a la falta de apoyo en muchos sentidos, pues las oportunidades laborales se complican cuando se tiene diversas responsabilidades en el hogar. La mayoría de las jefas de hogar monoparentales no pueden trabajar lo suficiente para generar la cantidad de ingreso que les permita salir de la Línea de la Pobreza.

En 2017 había 67,916 hogares unipersonales y estaban en condición de pobreza, los hogares más afectados son aqueIlos que eran jefeados por una mujer, en la zona urbana el $11.0 \%$ eran pobres extremos y un $13.6 \%$ no cubrían el costo de la canasta básica, sin embargo, también son afectados los hogares que los jefes son hombres el $6.1 \%$ estaban en condición de pobreza extrema y el $10.2 \%$ en pobreza relativa. En la zona rural las condiciones son similares donde el $24.9 \%$ de los hogares que reconocían como jefa de hogar a una mujer no generaron los ingresos per cápita suficientes para cubrir el costo de la canasta básica de alimentos y un $2.9 \%$ no cubría el costo de la canasta básica. Por otra parte, el $16.6 \%$ de los hogares que son jefeados por hombres estaban en condición de pobreza extrema y un $4.1 \%$ en pobreza relativa (Cuadro $\mathrm{N}^{\circ} 4$ ).

6 Canasta Básica: Además de los alimentos básicos, satisface necesidades básicas como ser vivienda, educación, salud, transporte etc. 
Cuadro №4 Honduras: nivel de pobreza y tipología según zona de residencia y sexo del jefe del hogar, 2017

\begin{tabular}{|c|c|c|c|c|c|c|c|c|c|c|c|c|}
\hline \multirow{3}{*}{\multicolumn{3}{|c|}{$\begin{array}{l}\text { Zona de Residencia/sexo } \\
\text { jefe/Clasificación de la pobreza }\end{array}$}} & \multicolumn{10}{|c|}{ Tipología } \\
\hline & & & \multicolumn{2}{|c|}{ UniPersonal } & \multicolumn{2}{|c|}{ BiParental } & \multicolumn{2}{|c|}{ MonoParental } & \multicolumn{2}{|c|}{ Extenso } & \multicolumn{2}{|c|}{ Compuesto } \\
\hline & & & Total & $\%$ & Total & $\%$ & Total & $\%$ & Total & $\%$ & Total & $\%$ \\
\hline \multirow{6}{*}{ Total } & \multirow{3}{*}{ Hombre } & Extrema & 11326 & $10.4 \%$ & 340269 & $41.8 \%$ & 8810 & $3.8 \%$ & 192283 & $25.3 \%$ & 27083 & $20.1 \%$ \\
\hline & & Relativa & 8419 & $7.7 \%$ & 164022 & $20.2 \%$ & 2371 & $1.0 \%$ & 112672 & $14.8 \%$ & 22385 & $16.7 \%$ \\
\hline & & No pobres & 40893 & $37.4 \%$ & 250841 & $30.8 \%$ & 9651 & $4.2 \%$ & 141246 & $18.6 \%$ & 51321 & $38.2 \%$ \\
\hline & \multirow{3}{*}{ Mujer } & Extrema & 18251 & $16.7 \%$ & 22836 & $2.8 \%$ & 87038 & $37.5 \%$ & 119215 & $15.7 \%$ & 7074 & $5.3 \%$ \\
\hline & & Relativa & 10133 & $9.3 \%$ & 17325 & $2.1 \%$ & 53857 & $23.2 \%$ & 84057 & $11.1 \%$ & 8254 & $6.1 \%$ \\
\hline & & No pobres & 20372 & $18.6 \%$ & 18675 & $2.3 \%$ & 70645 & $30.4 \%$ & 110272 & $14.5 \%$ & 18294 & $13.6 \%$ \\
\hline \multirow{6}{*}{ Urbano } & \multirow{3}{*}{ Hombre } & Extrema & 3912 & $6.1 \%$ & 100254 & $24.3 \%$ & 4654 & $3.1 \%$ & 65160 & $14.8 \%$ & 9235 & $10.6 \%$ \\
\hline & & Relativa & 6566 & $10.2 \%$ & 124139 & $30.0 \%$ & 1116 & $0.7 \%$ & 88903 & $20.1 \%$ & 19933 & $23.0 \%$ \\
\hline & & No pobres & 25854 & $40.0 \%$ & 148234 & $35.9 \%$ & 6602 & $4.4 \%$ & 78043 & $17.7 \%$ & 33592 & $38.7 \%$ \\
\hline & \multirow{3}{*}{ Mujer } & Extrema & 7100 & $11.0 \%$ & 10847 & $2.6 \%$ & 42760 & $28.7 \%$ & 60976 & $13.8 \%$ & 3367 & $3.9 \%$ \\
\hline & & Relativa & 8817 & $13.6 \%$ & 16070 & $3.9 \%$ & 44768 & $30.1 \%$ & 72128 & $16.3 \%$ & 7297 & $8.4 \%$ \\
\hline & & No pobres & 12389 & $19.2 \%$ & 13772 & $3.3 \%$ & 48999 & $32.9 \%$ & 76339 & $17.3 \%$ & 13301 & $15.3 \%$ \\
\hline \multirow{6}{*}{ Rural } & \multirow{3}{*}{ Hombre } & Extrema & 7415 & $16.6 \%$ & 240015 & $59.9 \%$ & 4156 & $5.0 \%$ & 127123 & $40.0 \%$ & 17849 & $37.4 \%$ \\
\hline & & Relativa & 1854 & $4.1 \%$ & 39883 & $10.0 \%$ & 1256 & $1.5 \%$ & 23768 & $7.5 \%$ & 2452 & $5.1 \%$ \\
\hline & & No pobres & 15038 & $33.6 \%$ & 102607 & $25.6 \%$ & 3050 & $3.7 \%$ & 63203 & $19.9 \%$ & 17729 & $37.2 \%$ \\
\hline & \multirow{3}{*}{ Mujer } & \begin{tabular}{|l|} 
Extrema \\
\end{tabular} & 11152 & $24.9 \%$ & 11989 & $3.0 \%$ & 44278 & $53.0 \%$ & 58240 & $18.3 \%$ & 3707 & $7.8 \%$ \\
\hline & & \begin{tabular}{|l|} 
Relativa \\
\end{tabular} & 1315 & $2.9 \%$ & 1256 & $0.3 \%$ & 9089 & $10.9 \%$ & 11929 & $3.7 \%$ & 957 & $2.0 \%$ \\
\hline & & No pobres & 7983 & $17.8 \%$ & 4903 & $1.2 \%$ & 21646 & $25.9 \%$ & 33933 & $10.7 \%$ & 4993 & $10.5 \%$ \\
\hline
\end{tabular}

Fuente: Elaboración propia en base a datos de la EPHPM, INE 2017

El crecimiento económico es fundamental para la reducción de la pobreza pero no es suficiente, ya que existen otros factores que pueden afectar de una u otra manera la tasa de transformación del crecimiento en reducción de la pobreza (elasticidad pobreza/PIB), tales como: el nivel de inequidad en la distribución del ingreso; la tasa de dependencia de los hogares más pobres y la tasa de participación de las mujeres en el mercado laboral (León/CEPAL, 2008).

\subsection{Ingreso per cápita de los hogares}

El ingreso per cápita del hogar7 está compuesto por la suma de todos los ingresos mensuales de los miembros del hogar, los percibidos por el trabajo y los provenientes de otras fuentes como pensiones, subsidios, alquileres, remesas del exterior $u$ otras transferencias regulares en dinero (INE, 2009). Sin embargo, no todos los hogares declaran sus ingresos, en el 2001 sólo el $86 \%$ declaró sus ingresos y en el 2017 se mejora la captación de los ingresos y todos los hogares declararon ingresos.

De acuerdo con los datos de la EPHPM de mayo de 2001, el ingreso per cápita de los hogares extensos en donde los jefes de hogares eran hombres y estaban en condición de pobreza extrema era apenas de L.459.4, cabe mencionar

7 Ingreso per cápita: Ingreso total del hogar dividido entre los miembros del hogar que el tamaño de estos hogares era de 6 personas lo que refleja la vulnerabilidad y condiciones en que vivía esta población, cada miembro del hogar subsiste con menos de L.3.00 por día. En cambio, el ingreso per cápita de los hogares en pobreza relativa su ingreso fue de L.998.1. El problema de la pobreza no se limita al área rural también los hogares del área urbana son afectados por la pobreza (Cuadro $\mathrm{N}^{\circ}$ ).

En Honduras los hogares rurales presentan los niveles de pobreza más altos respecto de los hogares urbanos, lo que refleja la ineficiencia de las estrategias implementadas para reducción de la pobreza en las zonas rurales. Esta condición de pobreza en las zonas rurales está relacionada con una baja disponibilidad de trabajo en actividades económicas no agropecuarias, la baja escolaridad de la población que conforma la población económicamente activa y la precariedad de los puestos de trabajos generados en las actividades productivas, así como su baja productividad, estos factores son determinantes de la pobreza desde la perspectiva del ingreso (Barros, 2006).

Los hogares extensos de la zona urbana presentan ingresos de subsistencia que no les permiten satisfacer las necesidades básicas de alimentación. Los ingresos de los hogares que eran jefeados por hombres en pobreza 
Cuadro $\mathrm{N}^{\circ} 5$ Honduras: ingreso per cápita de los hogares por sexo, zona de residencia y clasificación de la pobreza según tipología 2001

\begin{tabular}{|c|c|c|c|c|c|c|c|c|}
\hline \multirow{2}{*}{\multicolumn{3}{|c|}{$\begin{array}{c}\text { Zona de Residencia/sexo/Clasificación de } \\
\text { la pobreza }\end{array}$}} & \multicolumn{6}{|c|}{ Tipología } \\
\hline & & & Total & UniPersonal & BiParental & MonoParental & Extenso & Compuesto \\
\hline \multirow{6}{*}{ Total } & \multirow{3}{*}{ Hombre } & Extrema & 460.8 & 939.5 & 443.3 & 717.6 & 459.4 & 445.9 \\
\hline & & Relativa & 971.0 & $1,442.8$ & 941.1 & 976.8 & 998.1 & $1,112.0$ \\
\hline & & No pobres & $2,852.0$ & $4,274.1$ & $2,850.4$ & $2,683.1$ & $2,377.8$ & $3,110.6$ \\
\hline & \multirow{3}{*}{ Mujer } & Extrema & 590.7 & 864.0 & 545.4 & 565.1 & 592.2 & 782.0 \\
\hline & & Relativa & $1,138.0$ & $2,109.1$ & $1,029.9$ & $1,129.1$ & $1,079.8$ & $1,637.8$ \\
\hline & & No pobres & $2,904.4$ & $5,701.7$ & $3,553.5$ & $2,544.5$ & $2,470.6$ & $2,460.6$ \\
\hline \multirow{6}{*}{ Urbano } & \multirow{3}{*}{ Hombre } & Extrema & 639.0 & 893.4 & 600.0 & $1,120.8$ & 664.6 & 656.4 \\
\hline & & Relativa & $1,142.9$ & $1,658.4$ & $1,109.5$ & $1,114.7$ & $1,186.6$ & $1,243.5$ \\
\hline & & No pobres & $3,267.6$ & $4,897.9$ & $3,244.5$ & $3,332.1$ & $2,740.3$ & $3,460.7$ \\
\hline & \multirow{3}{*}{ Mujer } & Extrema & 735.8 & $1,056.5$ & 606.0 & 736.0 & 721.2 & $1,099.5$ \\
\hline & & Relativa & $1,260.2$ & $2,511.4$ & $1,195.0$ & $1,230.9$ & $1,201.1$ & $1,635.0$ \\
\hline & & No pobres & $3,390.0$ & $5,897.2$ & $4,262.5$ & $2,975.9$ & $2,882.8$ & $2,656.4$ \\
\hline \multirow{6}{*}{ Rural } & \multirow{3}{*}{ Hombre } & Extrema & 354.8 & 973.7 & 352.6 & 459.4 & 332.7 & 314.7 \\
\hline & & Relativa & 707.6 & $1,215.7$ & 688.1 & 696.1 & 706.5 & 798.5 \\
\hline & & No pobres & $2,107.3$ & $3,071.2$ & $2,143.0$ & $1,750.5$ & $1,768.3$ & $2,196.9$ \\
\hline & \multirow{3}{*}{ Mujer } & Extrema & 414.6 & 505.0 & 442.6 & 379.5 & 434.0 & 325.6 \\
\hline & & Relativa & 829.0 & $1,020.8$ & 669.9 & 815.9 & 788.9 & $1,642.3$ \\
\hline & & No pobres & $1,890.4$ & $4,777.6$ & $1,477.6$ & $1,772.3$ & $1,708.7$ & $1,000.0$ \\
\hline
\end{tabular}

Fuente: Elaboración propia en base a datos de la EPHPM, INE 2001

extrema fueron de L.664.60 de igual manera los hogares en pobreza extrema y las jefas mujeres sus ingresos fueron de L.721.2. Esta condición de precariedad es más profunda en las zonas rurales donde hay diferencia de ingresos entre los hogares en extrema pobreza de la zona urbana. Esta población enfrenta verdaderos retos día a día donde carecen de condiciones y oportunidades laborales para generar ingresos que les permitan cubrir sus necesidades básicas.

La desigualdad en pobreza afecta también a los hogares monoparentales, biparentales, compuestos y en menor medida a los hogares unipersonales, lo que implica que cada día las personas están llevando menos ingresos a sus hogares y que la principal fuente de ingreso de los hogares sigue siendo los salarios, de allí la importancia en generar las condiciones y puestos de trabajo en los cuales la población pueda tener una remuneración digna y con accesos a los sistemas de previsión social.

- Ingreso per cápita de los hogares insuficiente para salir de la pobreza

El incremento del ingreso per cápita de los hogares es insuficiente para salir de la pobreza ya que para establecer si una persona es pobre o no, se considera el costo de una canasta básica, que varía según la zona de residencia, en 2017 según la metodología utilizada por el INE, para el cálculo de la pobreza se estimó en L. 3,352.48 el costo de la canasta básica en las zonas urbanas y de L.1,693.17 en las zonas rurales.

Según los datos de la EPHPM de mayo de 2017 el ingreso per cápita de los hogares pobres se incrementó, sin embargo, este incremento no fue suficiente para cubrir los costos de la canasta básica. Los hogares más afectados por la pobreza siguen siendo los extensos indistintamente del sexo del jefe del hogar. Los hogares extensos cuyo jefe era un hombre y estaba en condición de pobreza extrema en la zona urbana su ingreso per cápita fue de L. 1,118.7 esto sólo le permitía cubrir un $33 \%$ del costo de la canasta básica, similar condición se presenta en los hogares donde las mujeres son jefas y estaban en pobreza extrema donde el ingreso per cápita era de L1,025.0. y cubría un 30\% del costo de la canasta básica. Los hogares extensos que eran afectados por la pobreza relativa en la zona urbana sólo cubrían el $72 \%$ del costo de la canasta básica con los ingresos que se generaron indistintamente del sexo del jefe del hogar (Cuadro $\mathrm{N}^{\circ} 6$ ). 
Cuadro N6 Honduras: ingreso per cápita de los hogares por sexo, zona de residencia y clasificación de la pobreza según tipología 2017

\begin{tabular}{|c|c|c|c|c|c|c|c|c|}
\hline \multirow{2}{*}{\multicolumn{3}{|c|}{$\begin{array}{c}\text { Zona de Residencia/sexo/Clasificación de } \\
\text { la pobreza }\end{array}$}} & \multicolumn{6}{|c|}{ Tipología } \\
\hline & & & \multirow{2}{*}{$\begin{array}{l}\text { Total } \\
769.5\end{array}$} & \multirow{2}{*}{\begin{tabular}{|r|} 
UniPersonal \\
695.7
\end{tabular}} & \multirow{2}{*}{\begin{tabular}{r|} 
BiParental \\
755.3
\end{tabular}} & \multirow{2}{*}{\begin{tabular}{|r|} 
MonoParental \\
860.2 \\
\end{tabular}} & \multirow{2}{*}{\begin{tabular}{r|} 
Extenso \\
788.7
\end{tabular}} & \multirow{2}{*}{$\begin{array}{r}\text { Compuesto } \\
813.6\end{array}$} \\
\hline \multirow{6}{*}{ Total } & \multirow{3}{*}{ Hombre } & Extrema & & & & & & \\
\hline & & Relativa & $2,228.9$ & $2,457.3$ & $2,206.9$ & $1,706.6$ & $2,204.9$ & $2,480.5$ \\
\hline & & No pobres & $6,273.6$ & $9,231.2$ & $6,470.6$ & $5,428.6$ & $4,777.1$ & $7,231.7$ \\
\hline & \multirow{3}{*}{ Mujer } & Extrema & 852.0 & 794.7 & 883.3 & 863.9 & 841.3 & 933.2 \\
\hline & & Relativa & $2,320.5$ & $2,422.8$ & $2,472.9$ & $2,253.0$ & $2,310.4$ & $2,419.1$ \\
\hline & & No pobres & $6,019.3$ & $7,471.5$ & $7,668.6$ & $5,693.8$ & $5,229.1$ & $8,738.5$ \\
\hline \multirow{6}{*}{ Urbano } & \multirow{3}{*}{ Hombre } & Extrema & $1,101.9$ & 959.0 & $1,088.6$ & $1,062.2$ & $1,118.7$ & $1,209.5$ \\
\hline & & Relativa & $2,453.5$ & $2,743.1$ & $2,452.7$ & $1,841.2$ & $2,405.9$ & $2,609.2$ \\
\hline & & No pobres & $7,557.9$ & $11,401.8$ & $7,427.3$ & $6,194.3$ & $6,004.9$ & $9,051.8$ \\
\hline & \multirow{3}{*}{ Mujer } & Extrema & $1,042.0$ & $1,001.6$ & $1,030.9$ & $1,064.9$ & $1,025.0$ & $1,180.6$ \\
\hline & & Relativa & $2,459.9$ & $2,554.7$ & $2,551.8$ & $2,414.4$ & $2,449.0$ & $2,529.6$ \\
\hline & & No pobres & $7,076.6$ & $8,775.7$ & $8,733.5$ & $6,718.3$ & $6,123.8$ & $10,566.4$ \\
\hline \multirow{6}{*}{ Rural } & \multirow{3}{*}{ Hombre } & Extrema & 615.9 & 556.8 & 616.1 & 634.0 & 619.5 & 608.7 \\
\hline & & Relativa & $1,448.1$ & $1,445.2$ & $1,441.6$ & $1,586.9$ & $1,453.3$ & $1,434.2$ \\
\hline & & No pobres & $4,411.6$ & $5,499.6$ & $5,088.4$ & $3,771.0$ & $3,261.0$ & $3,783.0$ \\
\hline & \multirow{3}{*}{ Mujer } & Extrema & 668.3 & 663.0 & 749.6 & 669.7 & 648.9 & 708.4 \\
\hline & & Relativa & $1,474.1$ & $1,538.8$ & $1,463.3$ & $1,457.9$ & $1,472.4$ & $1,576.0$ \\
\hline & & No pobres & $3,647.3$ & $5,447.4$ & $4,677.8$ & $3,374.6$ & $3,216.3$ & $3,868.7$ \\
\hline
\end{tabular}

Fuente: Elaboración propia en base a datos de la EPHPM, INE 2017

En Honduras de cada 10 hogares biparentales, 6 eran pobres, donde el ingreso per cápita era insuficiente para cubrir el costo de la canasta básica y de alimentos, los hogares en extrema pobreza de la zona urbana jefeados por hombres solo cubrían el $32 \%$ de la canasta básica de alimentos, en cambio los hogares en pobreza relativa su ingreso solo cubría el $73 \%$, la condición de pobreza en los hogares urbanos jefeados por mujeres y en pobreza extrema no es diferente a la de los hogares jefeados por hombres donde su ingreso per cápita era de L.1,030.9 y el tamaño promedio del hogar era de 4 personas, esta situación es precaria ya que cada persona sobrevive con menos L.9.00 por día. Los hogares en condición de pobreza relativa jefeados por mujeres en el área urbana cubrían el $73 \%$ del costo de la canasta básica.

En la zona rural la situación de las personas que viven en condición de pobreza extrema es más deprimente, los hogares biparentales jefeados por hombres su ingreso per cápita fue de L.616.1 y para los hogares jefeados por mujeres fue de L.749.6. Por otro lado, los hogares jefeados por hombres en pobreza relativa el ingreso per cápita del hogar ascendió a L. 1,441.6 y los hogares jefeados por mujeres su ingreso per cápita fue de L. 1,463.3.

Al hablar de hogares monoparentales hay que tomar en cuenta que se trata de hogares con rostro de mujer, donde las mujeres hacen frente a gastos vitales y esenciales como la compra de alimentos, pago de alquileres, material escolar y el cuidado de sus hijos, entre otros. En la zona urbana los hogares jefeados por mujeres sólo cubrían el $32 \%$ de la canasta básica de alimentos y los hogares en pobreza relativa cubrían el $72 \%$ de la canasta básica, similar condición presenta los hogares que son jefeados por hombres y estaban en pobreza extrema. En la zona rural la situación empeora para las familias ya que los hogares son más grandes (entre 3 y 4 personas por hogar) y se generan menos ingresos, los hogares en extrema pobreza donde la mujer era jefa de hogar su ingreso per cápita fue L.669.7 y para los hogares en pobreza relativa fue de L. 1,457.9. Por otra parte, los hogares en extrema pobreza y jefeados por hombres su ingreso se situó en L.634.0 y para los hogares en pobreza relativa fue de L.1,586.9.

De acuerdo con los datos de la EPHPM de mayo de 2017, el $48.2 \%$ de los hogares compuestos eran pobres, el ingreso per cápita de estos hogares estaba por debajo de la línea de la pobreza. Hay brechas de ingreso per cápita que se marcan en el área urbana entre los hogares jefeados por hombres y mujeres en extrema pobreza, por un lado, los hogares en extrema pobreza jefeados por un hombre el ingreso per cápita era de L. 1,209.5 y los hogares en extrema pobreza jefeados por una mujer su ingreso per cápita fue de L.1,180.6, sin embargo, estos ingresos no son suficientes para cubrir las necesidades básicas de alimentación de los miembros del hogar. Entre los hogares en pobreza relativa 
se observa una mejoría en sus ingresos tanto en los hogares que son jefeados por hombres y mujeres respecto a los observados en el 2001. No obstante, este incremento en el ingreso per cápita de los hogares solo permite cubrir $78 \%$ de la canasta básica en aquellos hogares jefeados por hombres y un $75 \%$ en los hogares jefeados por mujeres.

En la zona rural esta situación de pobreza extrema y pobreza relativa es más precaria entre los hogares jefeados por hombres y mujeres ya que los ingresos del área urbana duplican a los del área rural donde el tamaño de los hogares era de 5 personas, el ingreso per cápita de los hogares en extrema pobreza jefeados por hombres fue de L. 608.7 que cada persona sobrevive con L.4.00 o menos por día y el ingreso per cápita los hogares en pobreza relativa fue de L.1,434.2, similar situación presentan los hogares en extrema pobreza jefeados por mujeres donde el ingreso per cápita fue de L. 708.4 y para los que se encontraban en pobreza relativa fue de L.1,576.0.

La pobreza en Honduras en 2017 afectó al 64.3\% de los hogares indistintamente de sus composición y tipología. En la zona urbana los hombres presentan un nivel mayor de ingreso respecto de las mujeres, similar situación se presenta en la zona rural donde los ingresos de los hogares de los hombres son mayores a la de las mujeres, sin embargo, estos ingresos no cubren el costo de la canasta básica y están bajo la línea de la pobreza.

\subsection{Indicadores sintético de pobreza (FGT) 2001}

La línea de pobreza ofrecen un criterio claro e inequívoco de pobreza con lo que se dispone de un mecanismo para determinar quiénes son pobres. La cuestión es cómo utilizar esa información para obtener uno o varios índices de pobreza, es decir, una serie de medidas globales que señalen la importancia o alcance de la pobreza y que permitan conocer su evolución a lo largo del tiempo y su sensibilidad a las políticas que se pongan en práctica. Los principales indicadores o medidas agregadas de la pobreza se elaboran a partir de las líneas de pobreza y se agrupan en dos categorías: simples y compuestos (Dubois, s.f.)

\section{- Incidencia de la pobreza}

La incidencia de la pobreza mide el número de hogares pobres, osea la proporción de hogares cuyo consumo o renta está por debajo de la línea de la pobreza.

En Honduras la evolución de la incidencia de la pobreza por tipo de hogar muestra un comportamiento disímil tanto a nivel nacional como por zona de residencia, donde los hogares más afectados en el 2001 fueron en orden de afectación: los hogares extensos, monoparentales, biparentales, compuestos y en menor medida los unipersonales.

En la zona urbana los porcentajes más altos de incidencia de la pobreza la presentan los hogares extensos, monoparentales, biparentales y los hogares que presentan los porcentajes más bajos de incidencia estaban los compuestos y los hogares unipersonales.

La incidencia de la pobreza afecta más el ámbito rural, donde el $77 \%$ de los hogares extensos presentaban un déficit de ingreso per cápita que no fue suficiente para cubrir los costos de la canasta básica y alimentaria, en segundo lugar, se encontró a los hogares biparentales seguido de los hogares monoparentales y los hogares compuestos, por otro lado, los hogares unipersonales del área rural son los que presenta en el porcentaje de incidencia de la pobreza más bajo. Entre los factores que se asocian a la pobreza rural están las características geográficas, las actividades económicas, acceso a la educación, tamaño de las familias, características de las viviendas (Alcántara, 2008).

\section{- Brecha de la pobreza}

La brecha mide la profundidad de la pobreza, la distancia media que separa a la población de la línea de la pobreza, este indicador refleja que tan pobres son los pobres esto da una idea del tipo de carencia de ingreso o consumo que se da entre los pobres. Representa el déficit promedio de ingreso de los hogares para satisfacer las necesidades mínimas de bienes y servicios de todos los miembros del hogar, en otras palabras, es la cantidad de ingresos que sería necesario para sacar a los hogares pobres de la pobreza.

En 2001 en la zona urbana los hogares que presentan los déficits de ingresos más altos son los hogares unipersonales ya que requeriría un $50.4 \%$ de los ingresos para reducir el déficit de la línea de la pobreza, seguido de los hogares monoparentales y los biparentales. Este indicador refleja la dura realidad a la que se enfrentan día a día los hogares más pobres de Honduras, la brecha de la pobreza toma valores entre 0 y 1 entre más cercano este a 1 significa que los hogares necesitan más ingresos para cubrir el costo de la canasta básica y de alimentos y entre más cercano este de cero significa que los hogares requieren menos ingresos 
para salir de la pobreza.

El cuadro $\mathrm{N}^{\circ} .7$ revela que los coeficientes de brecha de la pobreza más altos se presentan en la zona rural lo que es congruente con la incidencia de la pobreza. En los hogares monoparentales el déficit de ingreso alcanzó el 59.4\%, seguido de los hogares biparentales y compuestos, el coeficiente de brecha más bajo se presentó en los hogares unipersonales, sin embargo los hogares en pobreza en 2001 no generaron los ingresos suficientes para cubrir el costo de la canasta básica y alimentaria y se presentó un déficit de ingreso superior a $56 \%$ en promedio, en otras palabras los hogares requerían duplicar e incrementar su ingreso per cápita para llegar a la línea de la pobreza o pobreza cero.

La situación pobreza y déficit de ingreso de los hogares urbanos no es distinta a los del área rural los coeficientes de brecha son altos, lo que muestra la necesidad que existe de mejorar las condiciones de ingreso y de vida de la población, mejorando la empleabilidad en donde las personas puedan acceder al mercado laboral y tener empleos dignos que les permita cubrir el costo de la canasta básica de alimentos y sobre todo tener acceso a la educación, salud y los servicios básicos (agua, saneamiento, electricidad etc.), y de igual manera es necesario mejorar la focalización de las transferencias en efectivo a los hogares que necesitan de estos recursos para salir de la pobreza.

\subsection{Intensidad de la pobreza}

La intensidad de la pobreza permite conocer hasta qué punto la pobreza afecta a la población pobre, por lo tanto, se centra en el grado de pobreza que sufren las personas, más que en el número de individuos considerados pobres. Uno de los factores que más influyen en la gravedad del fenómeno de la pobreza es su intensidad. Utilizar medidas relativas no aporta información del grado de pobreza de los pobres. Es necesario por tanto utilizar juntamente con las medidas relativas algún indicador de la profundidad de la pobreza que proporcione información de la situación económica de los pobres y de sus diferencias con el resto de la población.

Este indicador mide la situación de los pobres pues al interior de los mismos se observa una variedad de situaciones. Por un lado, se puede tener un porcentaje elevado de pobres en donde todos estén situados muy cerca del umbral, hasta otro en la que exista un pequeño porcentaje de pobres muy alejados del umbral de la pobreza (Estadística, 2005).

En 2001 a nivel nacional los porcentajes de severidad más alta se observó en los hogares biparentales, extensos y monoparentales y el porcentaje más bajo se registró en los hogares unipersonales.

Por zona de residencia se observa que la intensidad de la

Cuadro №7 Honduras: indicadores de pobreza seleccionados, según tipología del hogar urbano rural 2001

\begin{tabular}{|l|r|r|r|r|r|}
\hline \multirow{2}{*}{ Indicadores } & \multicolumn{5}{|c|}{ Tipología del Hogar } \\
\hline Total & Unipersonal & Biparental & Monoparental & Extenso & Compuesto \\
\hline Incidencia & 0.280 & 0.647 & 0.658 & 0.713 & 0.527 \\
\hline Brecha & 0.501 & 0.544 & 0.541 & 0.520 & 0.462 \\
\hline Intensidad & 0.141 & 0.354 & 0.339 & 0.355 & 0.226 \\
\hline Severidad & 0.089 & 0.234 & 0.224 & 0.231 & 0.139 \\
\hline Urbano & & & & & \\
\hline Incidencia & 0.230 & 0.552 & 0.629 & 0.659 & 0.430 \\
\hline Brecha & 0.504 & 0.476 & 0.488 & 0.464 & 0.356 \\
\hline Intensidad & 0.111 & 0.259 & 0.287 & 0.296 & 0.149 \\
\hline Severidad & 0.068 & 0.156 & 0.179 & 0.176 & 0.077 \\
\hline Rural & & & & & 0.682 \\
\hline Incidencia & 0.376 & 0.744 & 0.698 & 0.774 & 0.581 \\
\hline Brecha & 0.499 & 0.588 & 0.594 & 0.571 & 0.581 \\
\hline Intensidad & 0.186 & 0.436 & 0.400 & 0.416 & 0.349 \\
\hline Severidad & 0.120 & 0.301 & 0.276 & 0.288 & 0.239 \\
\hline
\end{tabular}

Fuente: Elaboración propia en base a datos de la EPHPM, INE 2001 
pobreza es más alta en los hogares rurales respecto de los hogares urbanos, lo que significa el grado de profundidad de la pobreza que en Honduras sufren más déficit de ingreso los hogares de la zona rural. En el área urbana el grado de intensidad más alto se registró en los hogares extensos, monoparentales y biparentales. En cambio, en la zona rural el grado de intensidad más alto se observó en los hogares biparentales, extensos y monoparentales.

\subsection{Severidad de la pobreza}

Severidad de la pobreza este indicador hace referencia a la situación de los más pobres, entre los pobres, cuanto más altos son los valores de este indicador significará que el ingreso de los pobres se encuentra más distante que el ingreso del conjunto de los pobres.

A nivel nacional los hogares extensos, biparentales y monoparentales son los que presentan los porcentajes más altos de severidad de la pobreza. Sin embargo, los datos muestran por zona de residencia que la pobreza afecta en mayor medida a los hogares rurales, y se observa las grandes carencias de ingreso con la que subsisten los hogares en estas zonas relegadas y olvidadas donde las condiciones socioeconómicas prevalecen como la falta de oportunidades para generar empleo, acceso a la tierra educación y salud entre otras. Ante estas condiciones manifiestas de pobreza en los hogares es indispensable generar proyectos que se oriente a la reducción de la pobreza en las zonas rurales.

Los hogares pobres pasaron de $65.2 \%$ en el 2001 a $64.3 \%$ en el 2017 porcentualmente se registra una reducción de 0.9 puntos porcentuales, sin embargo, en términos absolutos se registra un incremento de hogares pobres de 696,872 lo que refleja que las condiciones de la población y las desigualdades de ingreso se han agudizado en los últimos 16 años.

\subsection{Evolución de los indicadores sintético de pobreza (FGT) 2017}

En Honduras, el avance de reducción de la pobreza no ha sido significativo, en 16 años las condiciones de vida de la población no han mejorado, si bien es cierto que se registra un incremento leve en los ingresos de los hogares pobres el mismo no es suficiente para sacar a los hogares de la pobreza. De continuar esta tendencia observada a lo largo de los años es difícil que se cumplan las metas establecidas en los ODS de reducir la pobreza.

- Incidencia de la pobreza
En 2017 el indicador de incidencia registra un incremento en los hogares unipersonales y los hogares biparentales lo que refleja que los bonos gubernamentales y las ayudas que reciben los hogares tienen que focalizarse en los hogares que están en estas condiciones de pobreza donde los ingresos que generan no cubren los costos de la canasta básica y de alimentos.

La reducción del ingreso en los hogares pobres tiene un efecto negativo e impacta en el incremento del número de hogares pobres relativos y extrema. Según zona de residencia el número de hogares pobres unipersonales y biparentales se incrementó en la zona urbana y rural.

\section{- Brecha de la pobreza}

La brecha de la pobreza mide la cantidad per cápita de recursos necesarios para salir de la pobreza, este indicador permite observar que las transferencias condicionadas no han tenido el efecto esperado de reducir la pobreza en Honduras.

Por zona de residencia la brecha más alta se registra en los hogares de las zonas rurales biparentales, compuestos, unipersonales, extensos y monoparentales la brecha indica la cantidad de ingresos adicionales que requiere un hogar para salir de la línea de la pobreza o llegar a la pobreza cero.

En la zona urbana la brecha más alta se presenta en los hogares monoparentales que en su mayoría son jefeados por mujeres, seguida de los hogares extensos, biparentales y unipersonales y la brecha más baja se registra en los hogares compuestos (Cuadro $\mathrm{N}^{\circ}$. 8).

\section{- Intensidad de la pobreza}

La intensidad refleja la precariedad de los ingresos entre los hogares pobres entre más alto este porcentaje más profunda es el nivel de déficit de ingreso. A nivel nacional este indicador muestra una leve mejoría en los hogares extensos, biparentales, monoparentales y compuestos, sin embargo, esta mejoría no se refleja a nivel de reducción de hogares pobres ya que el incremento del ingreso no fue suficiente para sacarlos del umbral de la pobreza.

Por zona de residencia se observó que los hogares unipersonales, biparentales, monoparentales y compuestos de la zona urbana presentaron un incremento en la severidad de la pobreza respecto del 2001 y que se registra 
Cuadro №8 Honduras: indicadores de pobreza seleccionados, según tipología del hogar urbano rural 2017

\begin{tabular}{|l|r|r|r|r|r|}
\hline \multirow{2}{*}{ Indicador } & \multicolumn{5}{|c|}{ Tipología del Hogar } \\
\cline { 2 - 6 } & Unipersonal & Biparental & Monoparental & Extenso & Compuesto \\
\hline Total & & & & & \\
\hline Incidencia & 0.440 & 0.669 & 0.654 & 0.669 & 0.482 \\
\hline Brecha & 0.482 & 0.510 & 0.500 & 0.495 & 0.437 \\
\hline Intensidad & 0.212 & 0.341 & 0.327 & 0.331 & 0.211 \\
\hline Severidad & 0.137 & 0.217 & 0.203 & 0.206 & 0.124 \\
\hline Urbano & & & & & \\
\hline Incidencia & 0.408 & 0.608 & 0.627 & 0.650 & 0.459 \\
\hline Brecha & 0.419 & 0.447 & 0.486 & 0.454 & 0.359 \\
\hline Intensidad & 0.171 & 0.272 & 0.305 & 0.295 & 0.165 \\
\hline Severidad & 0.104 & 0.159 & 0.183 & 0.172 & 0.083 \\
\hline Rural & & & & & 0.695 \\
\hline Incidencia & 0.486 & 0.732 & 0.704 & 0.695 & 0.524 \\
\hline Brecha & 0.559 & 0.564 & 0.522 & 0.549 & 0.562 \\
\hline Intensidad & 0.272 & 0.413 & 0.368 & 0.382 & 0.294 \\
\hline Severidad & 0.183 & 0.277 & 0.239 & 0.254 & 0.199 \\
\hline
\end{tabular}

Fuente: Elaboración propia en base a datos de la EPHPM, INE 2017

una mejoría en este indicador en los hogares extensos. Por otro lado, hogares de la zona rural presenta una condición similar, no obstante, se registra un descenso en los hogares biparentales, monoparentales, extensos y compuestos pero que no tiene impacto positivo ya que lejos de acércalos a la línea de pobreza los ingresos de estos hogares siguen siendo bajos.

- Severidad de la pobreza

En 2017 el 66.9\% de los hogares biparentales estaban en condición de pobreza, hogares cuyos ingresos no lograron cubrir los costos de la canasta básica y alimentos este indicador de severidad hace referencia a la situación de los más pobres dentro de los pobres, cuanto más alto es este indicador significará que el ingreso de los pobres, se encuentra más distante que el ingreso del conjunto de pobres, en este sentido a nivel nacional se observa un grado de severidad de $21.7 \%$ en los hogares biparentales, seguido de los hogares extensos, monoparentales y los porcentajes más bajos se registra en los hogares compuestos y unipersonales.

En la zona urbana las condiciones de pobreza son disímiles entre la tipología de los hogares pobres donde los porcentajes de severidad más altos se registró en los hogares monoparentales, seguido de los hogares extensos y en tercer lugar están los hogares biparentales y los porcentajes más bajos se observó en los hogares compuestos y unipersonales.
La desigualdad se incrementa más en las zonas rurales donde los porcentajes más altos de severidad de la pobreza se presenta en los biparentales, extensos y monoparentales, y los porcentajes más bajos se registran en los hogares unipersonales y compuestos.

\section{Conclusiones}

Honduras está inserto en un proceso de transición rural urbano ya que en el 2001 los hogares rurales eran los que predominaban, sin embargo 16 años después predominan los hogares urbanos. De acuerdo a la tipología presentada en la investigación el tamaño de los hogares biparentales y los extensos se han reducido. La edad mediana se incrementó en los biparentales pasando de 39 a 40 años y en los hogares compuestos pasó de 49 a 54 años. Los hogares monoparentales tienen rostro femenino y están conformados en su mayoría por mujeres y la edad mediana fue de 42 años y el tamaño pasó de 4 en el 2001 a 3 en el 2017.

La pobreza por ingreso es sinónimo de carencia y privación, que limita a una persona para alcanzar un mínimo de nivel de vida. En los últimos 16 años las condiciones de vida de la población en general no han mejorado, ya que se ha incrementado el número de hogares en condición de pobreza extrema y relativa. En 16 años se observó una leve mejora en los ingresos de los hogares pobres, sin embargo, este incremento no fue significativo ya que el dinero 
alcanza cada vez menos, lo que ha hecho que la pobreza mantenga una línea ascendente en su comportamiento. No se puede salir de la pobreza si no se cuenta con un ingreso suficiente para satisfacer las diferentes necesidades de los hogares. Las zonas rurales presentan los niveles más altos de pobreza extrema tanto en el 2001 como en el 2016 ya que es una zona olvidada por los gobiernos donde más del $60 \%$ de los hogares viven con menos de un dólar por día. La pobreza afecta a los hogares indistintamente del sexo del jefe del hogar, sin embargo, este problema de pobreza afecta en mayor proporción a los hogares que son jefeados por mujeres y viven en las zonas rurales.

Honduras es un país donde históricamente persisten las desigualdades; los ingresos se concentran en el $20 \%$ de la población más rica y las transferencias condicionadas no tienen el efecto esperado de reducir la pobreza. La pobreza no solo afecta a los hogares de la zona urbana, también alcanza a los hogares de la zona rural donde los hogares viven en condiciones deplorables y presentan un déficit de ingreso superior a los hogares de la zona urbana. En 2001 según tipología los hogares que presentaron los niveles más altos de pobreza, de manera ordinal fueron: los hogares extensos, monoparentales, biparentales y compuestos, 16 años después se sigue manteniendo estos niveles de pobreza en estos hogares por lo que se infiere que el esfuerzo del Gobierno por reducir la pobreza no ha sido efectivo y que hay que mejorar las transferencias condicionadas focalizando los hogares que están en condición de pobreza.

Los indicadores (FGT) de incidencia, brecha, intensidad y severidad a lo largo de la investigación permitió profundizar y conocer las carencias de ingreso que se presentan entre los hogares pobres, extremos y relativa y sobre las brechas de ingreso que se presentan entre zonas de residencia urbano y rural. Los ingresos de los hogares pobres de la zona urbana duplican los ingresos de los hogares pobres de la zona rural, sin embargo, la pobreza afecta a los hogares de ambas zonas donde los niveles de ingreso no les permite cubrir el costo de la canasta básica de alimentos.

\section{Bibliografía}

- Alcántara, M. (2008). fao.org. Obtenido de http://www. fao.org/family-arming/detail/es/c/358088/

- Barros, P. d. (2006). Erradicar la pobreza extrema y el hambre.

- CEPAL. (2004). Población, Envejecimiento y Desarrollo. San Juan, Puerto Rico.

- De Oliveira, G. B. (1982). Hogares y Trabajadores en la Ciudad de México. UNAM, México.

- Dubois, A. (s.f.). Diccionario de Acción Humanitaria y Cooperación al Desarrollo. Obtenido de www.dicc.hegoa. ehu.es/listar/mostrar/123

- Estadística, I. N. (2005). La Pobreza y su medición presentación de diversos métodos de obtención de medidas de pobreza. Madrid España.

- Fonseca, M. F. (2013). Tipología de los hogares. Tegucigalpa. INE. (2001). EPHPM, Metodología. Tegucigalpa, M.D.C.

- INE. (2009). Encuesta Permanente de Hogares de Propósito Múltiples. Tegucigalpa, M.D.C.

- León/CEPAL, A. (2008). Progreso en la reducción de la pobreza extrema en América Latina.

- Thomas Burch, L. F. (1976). La Familia como Estudio Demogáfico. San José, Costa Rica, 1976: CELADE. 